\title{
The Effect of the Dry Line and Convective Initiation on Drought Evolution over Oklahoma during the 2011 Drought
}

\author{
Paul X. Flanagan, ${ }^{1,2}$ Jeffrey B. Basara, ${ }^{1,2}$ Bradley G. Illston, ${ }^{2}$ and Jason A. Otkin ${ }^{3}$ \\ ${ }^{1}$ School of Meteorology, University of Oklahoma, Norman, OK, USA \\ ${ }^{2}$ Oklahoma Climatological Survey, Norman, OK, USA \\ ${ }^{3}$ Cooperative Institute for Meteorological Satellite Studies, Space Science and Engineering Center, \\ University of Wisconsin-Madison, Madison, WI, USA \\ Correspondence should be addressed to Paul X. Flanagan; pxf11@ou.edu
}

Received 7 February 2017; Accepted 9 May 2017; Published 4 July 2017

Academic Editor: Pedro Jiménez-Guerrero

Copyright (C) 2017 Paul X. Flanagan et al. This is an open access article distributed under the Creative Commons Attribution License, which permits unrestricted use, distribution, and reproduction in any medium, provided the original work is properly cited.

\begin{abstract}
Observations from the Oklahoma Mesonet and high resolution Weather Research and Forecasting model simulations were used to evaluate the effect that the dry line and large-scale atmospheric patterns had on drought evolution during 2011. Mesonet observations showed that a "dry" and "wet" pattern developed across Oklahoma due to anomalous atmospheric patterns. The location of the dry line varied due to this "dry" and "wet" pattern, with the average dry line location around $1.5^{\circ}$ longitude further to the east than climatology. Model simulations were used to further quantify the impact of variable surface conditions on dry line evolution and convective initiation (CI) during April and May 2011. Specifically, soil moisture conditions were altered to depict "wet" and "dry" conditions across the domain by replacing the soil moisture values by each soil category's porosity or wilting point value. Overall, the strength of the dry line boundary, its position, and subsequent CI were dependent on the modification of soil moisture. The simulations demonstrated that modifying soil moisture impacted the nature of the dry line and showed that soil moisture conditions during the first half of the warm season modified the dry line pattern and influenced the evolution and perpetuation of drought over Oklahoma.
\end{abstract}

\section{Introduction}

The Great Plains (GP) of the United States (US) is a region marked by periods of drought at multiple spatial and temporal scales ([1]; Christian et al., 2015). While drought impacts numerous regions of the United States [2], a lack of measurable precipitation in the GP, extended periods of anomalously high temperatures, misuse of natural resources, or a combination of the above yields vast impacts on the landscape and the ecosystem in the GP. For example, during the 1930s, intense decadal drought $[3,4]$ produced catastrophic socioeconomic impacts that led to substantial social migration out of the region due to the loss of crops and resources vital for the survival of livestock [5]. Even though current agricultural practices have improved and soil conservation practices have significantly reduced erosion in the GP, the region remains markedly susceptible to drought conditions.
Many contributing factors drive drought evolution in the GP including persistent synoptic patterns (e.g., Namais, 1983, and [6-9]), teleconnection patterns and sea surface temperature anomalies (e.g., [10-16]), and surface-atmosphere coupling (e.g., $[12,17,18])$. Further, drought can persist at temporal scales spanning several years to decades, such as the "Dust Bowl" of the 1930s and intense drought during the 1950s, while also developing rapidly during the warm season over periods as short as a few weeks [19-21].

As drought develops and evolves, surface characteristics change due to limited precipitation. For example, during the warm season, soils quickly dry due to increased evapotranspiration rates and vegetation may reach the wilting point without additional rainfall. Such vegetation changes impact the surface energy balance, as areas with less root-zone soil moisture partition the available net energy towards sensible heating while latent heat flux decreases. The exchange of heat and moisture between the surface and the atmosphere 
further impacts the structure and development of the planetary boundary layer (PBL $[22,23])$ and such interactions between the surface conditions and the overlying atmosphere in the GP can modify atmospheric instability, convective precipitation, and regional precipitation coupling [24-27].

At the same time, during the early warm season, precipitation and convective storm development in the Southern Great Plains (SGP) is influenced by the dry line [28, 29], a mesoscale boundary dividing dry, continental air to the west from moist, maritime air to the east (Hoch and Markowski, 2004, [28], and Schaefer, 1974a, 1974b). This is important for convective storm initiation during the early warm season and land-atmospheric coupling has been a focus of many dry line studies to deduce the effect of the land surface on dry line formation and development. Grasso [30] modeled the effect of differing soil moisture distributions on a specific dry line case and found that dry line propagation during the day is sensitive to changes in soil moisture. Further, when a constant soil moisture value was used over the domain, expansive dry line propagation did not occur. Ziegler et al. [31] modeled the sensitivity of dry line formation to differing soil moisture distributions using the Colorado State University Regional Atmospheric Modeling System (CSU-RAMS). The authors found that a west-to-east volumetric soil moisture gradient of 0.35 to $0.50 \mathrm{~m}^{3} / \mathrm{m}^{3}$ over $50 \mathrm{~km}$ was sufficient to initiate dry line formation, while a dry line was not produced when volumetric soil moisture was held constant at a value of either 0.35 or $0.50 \mathrm{~m}^{3} / \mathrm{m}^{3}$. The authors also found a connection between surface heat flux, boundary layer growth, and the strength of the surface moisture boundary. With less surface heat flux (their short grass and moderate soil moisture cases), Ziegler et al. [31] found that boundary layer growth was suppressed which further resulted in a weaker dry line than the control case. In addition, the study found that low-level convergence was less pronounced in these cases and that dry line formation was inhibited. Shaw et al. [32] showed that to accurately predict the dry line, the dry line morphology must be accurately tied to soil moisture and vegetation variability. The authors mention that a reduction of soil moisture over the entire domain caused an increase of sensible heat fluxes and a reduction of the west-to-east virtual temperature gradient. This allowed the moist air ahead of the surface boundary to mix more efficiently and thus the moisture gradient propagated further to the east with a slightly faster eastward movement. Shaw et al. [32] also theorized that moist soils ahead of the dry line could play a role in the maintenance of the strong moisture gradient at the boundary through faster transport of local moisture towards the dry line moisture gradient as opposed to transport from a source further away (e.g., the Gulf of Mexico). The authors conclude by noting that a fundamental relationship between the dry line and land surface conditions exists which yields an interesting question of cause and effect. For example, if this feature is influenced by the surface, how does the dry line's influence on surface conditions further affect the dry line itself?

During 2011, intense drought developed across the SGP [33], which yielded significant drought-related impacts across Texas and Oklahoma [34]. However, as drought evolved across Oklahoma an east-west gradient in drought severity developed in which areas to the east received significant precipitation while areas to the west received limited precipitation. As a result, a strong gradient in soil moisture conditions also developed across the region.

While the complex interactions between the dry line and the land surface have been extensively investigated, the connections between drought development, the dry line, and land-atmosphere interactions have not. Thus, this study examines the interrelationships between the dry line, convective initiation (CI), precipitation, and the evolution of drought across Oklahoma during 2011 using in situ observations and numerical simulations via the Weather Research and Forecasting Advanced Research (WRF-ARW) model. The overall goal was to determine the role of the dry line on surface conditions during the progression of drought and how these conditions influenced the dry line during the warm season.

\section{Methodology}

2.1. Oklahoma Mesonet. Oklahoma Mesonet (hereafter called Mesonet) data $[35,36]$ was used to analyze the soil and nearsurface atmospheric conditions over the period spanning March through August of 2011. The Mesonet is an automated network of 121 stations (Figure 1) installed across the state of Oklahoma that collects observations of soil and atmospheric variables at 5-30-minute intervals. Each observing station includes a datalogger, solar panel, radio transceiver, lightning rod, and environmental sensors attached to, or surrounding, a $10 \mathrm{~m}$ tower [36]. To minimize the impacts of bare soil and fast growing vegetation, the stations are placed in areas with uniform, low-growing vegetation. The sensor layout is designed to obtain the highest quality data possible [37].

To gain a better understanding of the drought evolution, $2 \mathrm{~m}$ temperature and specific humidity and $10-\mathrm{m}$ wind speed along with precipitation totals and soil moisture values collected by the Mesonet were analyzed. Anomalies were calculated from a station long-term average dataset spanning 1999-2014 if at least $80 \%$ of the observations from a given variable, period, and station were recorded in the dataset. This is especially important for the soil moisture anomalies given that the stations changed from 2000 to 2007, with 6 sites upgraded and 5 decommissioned [38]. The collected data were analyzed in terms of monthly averages. Daily averages and anomalies were investigated; however the monthly anomalies showed the same overall trends as the daily values and thus were used. A key point of caution in this analysis involves the use of monthly $5 \mathrm{~cm}$ soil moisture anomalies, as shallow soil moisture can change rapidly due to discrete recharge events [39].

2.1.1. Soil Moisture Data. Soil moisture is measured by the Campbell Scientific 229-L heat dissipation sensor at depths of 5,25 , and $60 \mathrm{~cm}[36,38,41]$. Soil moisture measurements are not available at all stations at each depth due to sitespecific limitations (e.g., shallow bedrock) and are measured to a depth of $5 \mathrm{~cm}$ at 108 sites, $25 \mathrm{~cm}$ at 106 sites, and $60 \mathrm{~cm}$ at 


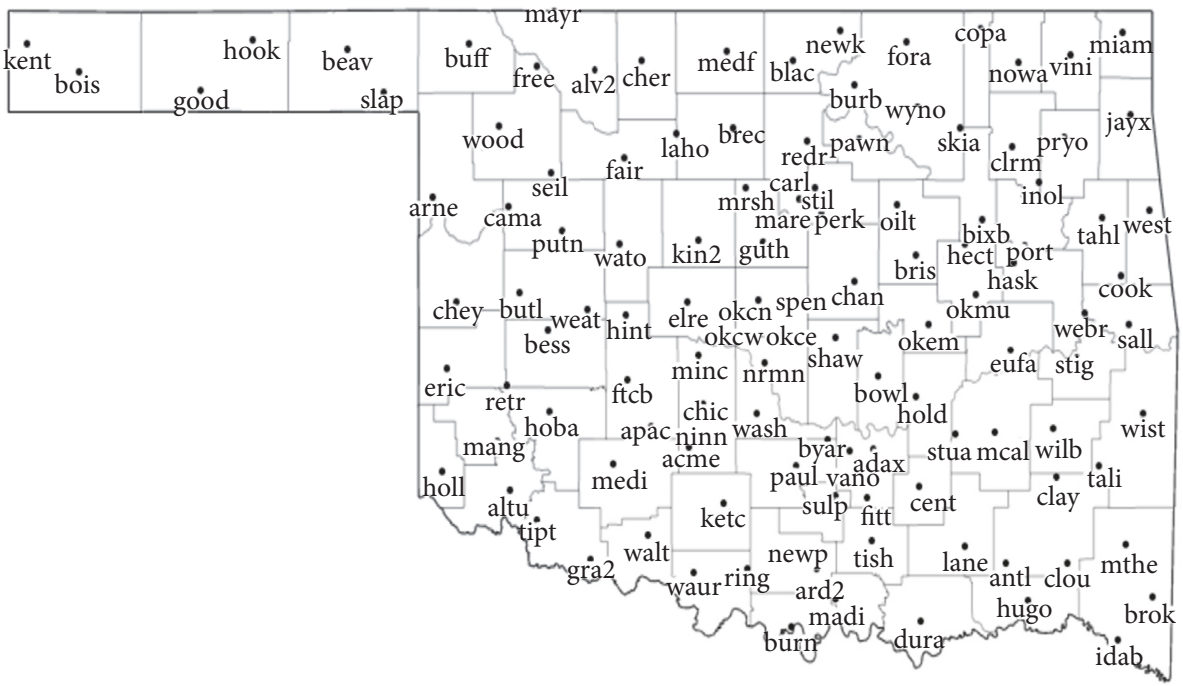

Oklahoma Mesonet Stations

As of March 1, 2011

FIgURE 1: The Oklahoma Mesonet: stations displayed as of March 1, 2011.

82 sites as of 2011 [38]. The variable used for this study is the Fractional Water Index (FWI), which is a normalized index for soil moisture calculated via [38]

$$
\mathrm{FWI}=\frac{\Delta T_{d}-\Delta T_{\mathrm{ref}}}{\Delta T_{d}-\Delta T_{w}},
$$

where $\Delta T_{\text {ref }}$ is reference temperature difference, $\Delta T_{d}=$ $3.96^{\circ} \mathrm{C}$, and $\Delta T_{w}=1.38^{\circ} \mathrm{C}$. The sensor is buried at the depth specified [41] and measures the response to a pulse of heat caused by a $50 \mathrm{~mA}$ current (for 21 seconds) passing through the resistor located next to the thermocouple itself located within a ceramic matrix [38]. The difference between the soil temperature after the pulse and the temperature before the pulse is used to derive $\Delta T_{\text {ref }}$, by using a linear regression to normalize the response of the individual sensor to an idealized sensor with a maximum $\Delta T$ of $3.96^{\circ} \mathrm{C}$ and a minimum $\Delta T$ of $1.38^{\circ} \mathrm{C}$ to derive sensor specific calibration coefficients, which are then used to calculate $\Delta T_{\text {ref }}$. This gives a maximum value of FWI at 1 , no change in temperature between pulses $\left(\Delta T_{\text {ref }}=1.38^{\circ} \mathrm{C}\right)$, and a minimum value of 0 , a maximum change in temperature $\left(\Delta T_{\text {ref }}=3.96^{\circ} \mathrm{C}\right)$. FWI is a useful quantitative measure because it is not impacted by differing soil types. It is also important to note that the majority of vegetation in Oklahoma will flourish when FWI is above 0.8 , begin to wilt when FWI is around 0.5 , and begin to perish when FWI values are less than 0.3 [40].

2.1.2. Specific Humidity Data. Specific humidity $\left(\mathrm{kg} \mathrm{kg}^{-1}\right)$ is calculated using

$$
q=\frac{\varepsilon e}{(p-(1-\varepsilon) e)}
$$

where $\varepsilon=0.622$, $p$ is pressure $(\mathrm{hPa})$, and $e$ is vapor pressure (hPa) calculated from the Goff-Gratch [42] equation. Specific humidity is not measured directly, but rather computed from other measured quantities collected by the Mesonet (temperature, relative humidity, and air pressure).

2.2. Dry Line Classification. To determine the impact of the dry line on the environment, a dataset of dry line events was developed for March-August 2011. One of the defining features of Oklahoma is the east-to-west terrain height change. Use of dew point temperature and relative humidity would be impacted by this change of terrain height, so to remove this source of error the specific humidity field was used similar to that of Hoch and Markowski [43]. As such, a gradient of $3 \mathrm{~g} \mathrm{~kg}^{-1}(100 \mathrm{~km})^{-1}$ in the specific humidity field determined using Mesonet data was required to identify a dry line.

This analysis determined the largest distance between any two points across the identified boundary that contained a $3 \mathrm{~g} \mathrm{~kg}^{-1}$ gradient and then matched it against the prescribed dry line qualification criteria to determine if the identified boundary was a dry line. Analysis was completed at 0000 UTC to compare results with the Hoch and Markowski [43] study. During the analysis several active dry line cases were identified that had been overtaken by surface fronts prior to 0000 UTC. To include these dry line cases they were identified at 2100 UTC and are noted as such in the results. Dry line longitudes were determined following the Hoch and Markowski [43] methodology. As such, longitudes were found by taking the longitude of the easternmost point on the furthest east specific humidity contour that was analyzed as part of the dry line moisture gradient.

To determine if CI occurred along any identified dry line boundary, remotely sensed observations were used. The National Center for Atmospheric Research (NCAR) provides an archive of weather data that is publicly available at the Warm Season Precipitation Episodes (WSPE: http://www2.mmm.ucar.edu/episodes/) website. The archive includes visible satellite images and composite radar data 
for each day from 1996 to present. Dry line location was determined via Mesonet data and satellite images were used to identify convective clouds along the boundary. The longitude of CI was determined by the furthest west convective cloud that developed on or near the dry line via manual inspection of satellite data, with convective cloud formation determined using archived visible band Geostationary Operational Environmental Satellite (GOES) data from the NCAR WSPE website. Three classes of dry lines were determined from this analysis:

(1) A dry line that did not produce any convective clouds or precipitation

(2) A dry line that produced convective clouds but no precipitation

(3) A dry line that produced both convective clouds and precipitation

Production of precipitation was determined using Mesonet precipitation data in conjunction with the dry line position; however it is possible that dry line precipitation was not identified due to the limitations of the Mesonet observations (i.e., that a station was not in the area that received precipitation). The longitude of precipitation for each dry line event that produced precipitation was found by analyzing Mesonet data and determining the westernmost station that received rainfall (greater than or equal to $1 \mathrm{~mm}$ ) that could be traced back to storms that initiated along the dry line boundary. This was done so as not to artificially inflate the statistics that determine the furthest east station which received dry line produced precipitation as convection could occur some distance away from the actual dry line boundary. However, typical dry lines are quasi-linear boundaries [43] so with the method used to define the dry line longitude, rainfall longitudes may appear further to the west than the "mean" dry line that initiated the rainfall.

2.3. WRF-ARW Modeling Configuration. The WRF-ARW was used as the main investigation tool for the modeling portion of this study. A two-way nested grid configuration (Figure 2) was used with the outer domain covering $810 \times$ $710 \mathrm{~km}$ with $10 \mathrm{~km}$ horizontal grid spacing, and the inner domain covering $592 \times 452 \mathrm{~km}$ with $2 \mathrm{~km}$ horizontal grid spacing. Each domain had 114 vertical levels, with a model top of $50 \mathrm{hPa}$, using a mass-based terrain following vertical coordinate system. With regard to boundary layer vertical grid spacing a total of 13 vertical levels are below $2 \mathrm{~km}$ with a total of 18 vertical levels below $3 \mathrm{~km}$, the typical boundary layer height found in most of the simulations. The fine vertical resolution in the PBL promotes a realistic simulation of processes important to dry line formation and evolution. Boundary conditions over both domains were set using the North American Mesoscale (NAM) Forecast System $12 \mathrm{~km}$, 6 hourly update output data. Both domains utilized the Rapid Radiative Transfer Model (RRTM) longwave [44] and Dudhia [45] shortwave radiation schemes. The Unified NCEP/NCAR/AFWA Noah Land Surface Model was utilized to simulate surface conditions through all simulations with 4 soil layers and accounts for frozen soil and multilayer snow.

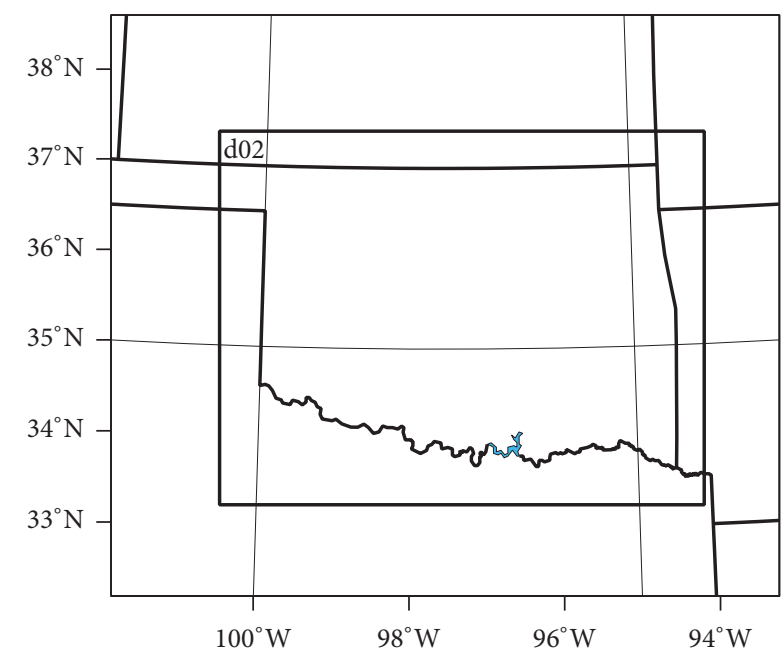

Figure 2: Map detailing the configuration of the nested domains used in WRF.

The Yonsei University PBL Scheme (YSU [46]) was chosen given the results of Gibbs et al. [47] which showed that the YSU scheme more accurately reproduced the observed surface heat fluxes over portions of Oklahoma compared to a local closure scheme. The Kain-Fritsch [48] cumulus scheme was used on the outer domain whereas no cumulus scheme was used on the inner domain. The Morrison 2moment microphysics scheme [49] was used over both domains. Comparison of simulations completed with different microphysics schemes in the inner domain showed that the Morrison double moment scheme outperformed the WDM-6 scheme [50] in the test case with regard to the location of precipitation (not shown).

2.3.1. Initialization of Surface Conditions and Sensitivity Analysis Design. To develop the initialization of soil conditions, the High Resolution Land Data Assimilation System (HRLDAS [51]) was used. This system is based on the Noah Land Surface Model (LSM $[52,53]$ ) and the Noah LSM's predecessor the Oregon State University (OSU) LSM [54-57] which uses input data to build a more accurate background of soil moisture and temperature. To achieve this, a 5-year spin-up period (2006-2011) was completed using HRLDAS and North American Regional Reanalysis (NARR) data for initialization and forcing. This duration was chosen due to analyses by Monroe et al. [2014] who noted large differences between short spin-up ( $<2$ years) simulations and simulations using a 5-year surface spin-up via HRLDAS. Cosgrove et al. [58] also noted that in the central Great Plains that spin-up for 49 months was required to reach a percent cutoff threshold (how long it takes for yearly changes in monthly averaged model output to decrease to a certain threshold) of $0.01 \%$, which represents fine scale model equilibrium with root-zone soil moisture. Thus, a longer spin-up duration of 5 years was required to reach a more representative surface state.

To quantify the impact of surface conditions on the dry line several simulations were completed in which the initial soil moisture conditions were altered. Instead of using 
TABLE 1: The soil moisture values used to replace Control soil moisture values in each wrfinput file with their associated soil type. Soil porosity values are for Moist simulations, and wilting point values replace soil moisture values in the Dry simulations. Numbers next to each soil type are the corresponding WRF soil type classifications used within the wrfinput file.

\begin{tabular}{lcc}
\hline Soil type & Soil porosity & Wilting point \\
\hline Sand (1) & $\Theta_{S}$ & $\Theta_{w}$ \\
Loamy sand (2) & 0.339 & 0.010 \\
Sandy loam (3) & 0.421 & 0.028 \\
Silt loam (4) & 0.434 & 0.047 \\
Silt (5) & 0.476 & 0.084 \\
Loam (6) & 0.476 & 0.084 \\
Sandy clay loam (7) & 0.439 & 0.066 \\
Silty clay loam (8) & 0.404 & 0.067 \\
Clay loam (9) & 0.464 & 0.120 \\
Sandy clay (10) & 0.465 & 0.103 \\
Silty clay (11) & 0.406 & 0.100 \\
Clay (12) & 0.468 & 0.126 \\
Organic material (13) & 0.468 & 0.138 \\
Water (14) & 0.439 & 0.066 \\
Bedrock (15) & & \\
Other (land-ice) (16) & 0.25 & 0.094 \\
\hline
\end{tabular}

homogenous (wet or dry) soil moisture conditions [31, 32] or a fractional $(-\%,+\%)$ change $[30,59]$ the sensitivity runs were initialized with soil moisture conditions based on the grid point soil type and maximum/minimum soil "wetness." As such, the magnitude of soil moisture was replaced by the wilting point (Dry) and soil porosity (Moist) of each soil type at each grid point throughout the soil depth as determined by the WRF Postprocessing System based on United States Geological Survey (USGS) soil categories. A description of these values is available in Table 1. Physically, this type of modification is a more realistic approach than using a homogenous modification of the magnitude of soil moisture given the available water in the soil is largely determined by soil texture.

\section{Drought and Dry Line Analysis}

3.1. Drought Analysis. During the months of April and May 2011 drought evolved in a distinct west-to-east pattern over the state of Oklahoma (Figure 3). Drought was established in southern Oklahoma at the beginning of April (Figure 3(a)) and conditions during April and May modified the evolution of drought towards a more east-west gradient of drought conditions (Figure 3(b)). To determine the surface environmental conditions that led to this drought evolution, Mesonet observations were analyzed. Precipitation was anomalously high in eastern Oklahoma during April and May, with western Oklahoma receiving much less rainfall (Figure 4). The precipitation anomalies depict the "dry and wet" pattern that occurred during the two months. This result was also depicted by Su and Dickinson [60] who modeled the SGP region in order to understand the spatial patterns of soil moisture-precipitation feedback during the month of April 2011. They found that atmospheric conditions were such that deep convection was inhibited over western Oklahoma and enhanced by moisture convergence in eastern Oklahoma. However, the main driver for the anomalous rainfall in April was due to synoptic features rather than the dry line. In contrast, the anomalous rainfall that occurred in May (4/9 rainfall events driven by dry lines) was produced more so by dry line events when compared to April (2/11 rainfall events driven by dry lines). This pattern of precipitation over the state provided the conditions that led to easing of drought conditions across eastern Oklahoma and drought intensification over western Oklahoma. Climatologically, the precipitation that normally occurs in this period is abundant over eastern Oklahoma while being crucial in western Oklahoma to stave off drought development as the warm season progresses. Illston et al. [40] noted that during phase II (transitional drying phase) the large fluctuations of FWI that are occurring, especially in western Oklahoma, are due to the variable rainfall that occurs in the region and recharges the soil moisture (Figure 5). As such, precipitation from March to June is important to the evolution of early warm season drought in Oklahoma. This is in contrast to the other phases (I, plateau phase; III, enhanced drying phase; $\mathrm{IV}$, recharge phase), which show a more consistent pattern. Thus, with little precipitation over western Oklahoma during these months, the drought continued to strengthen, while the copious amounts of precipitation in eastern Oklahoma eased drought conditions there. An area of interest during May is the region of anomalously high precipitation in west central Oklahoma (Figure 4(b)). These positive anomalies were caused by isolated dry line convection and other surface boundary events. An easing of drought occurred due to these rainfall events but overall did not have a significant impact on the overall evolution of drought conditions.

The surface temperature anomaly patterns were not similar in the months of April and May (Figure 6). In April, temperatures were largely above normal across the entire state. These conditions aided the development of drought across western Oklahoma as high temperatures along with a lack of precipitation dried out the surface. In eastern Oklahoma, the impact of these higher than average temperatures was lessened due to the copious amounts of rainfall. In May, however, a different pattern emerged. Temperature anomalies over central and eastern Oklahoma were below normal, by 0.2 to $1.3^{\circ} \mathrm{C}$, while western Oklahoma was above normal by 0.2 to $0.9^{\circ} \mathrm{C}$. This pattern would further enhance drought in extreme western Oklahoma while aiding in the easing of drought in the eastern portions of the state.

Analysis of soil moisture anomalies during April and May (Figure 7) depicts the effect that the anomalous precipitation and temperature patterns had on the surface. During April, the $5 \mathrm{~cm}$ FWI anomalies show near average $(-0.25$ to 0.10$)$ soil moisture in eastern Oklahoma, with below average ( 0.30 to $0.50)$ values in western Oklahoma. Even with the anomalous precipitation in eastern Oklahoma soil moisture values were not substantially above normal. This is likely due to the anomalous temperature pattern seen over Oklahoma that 


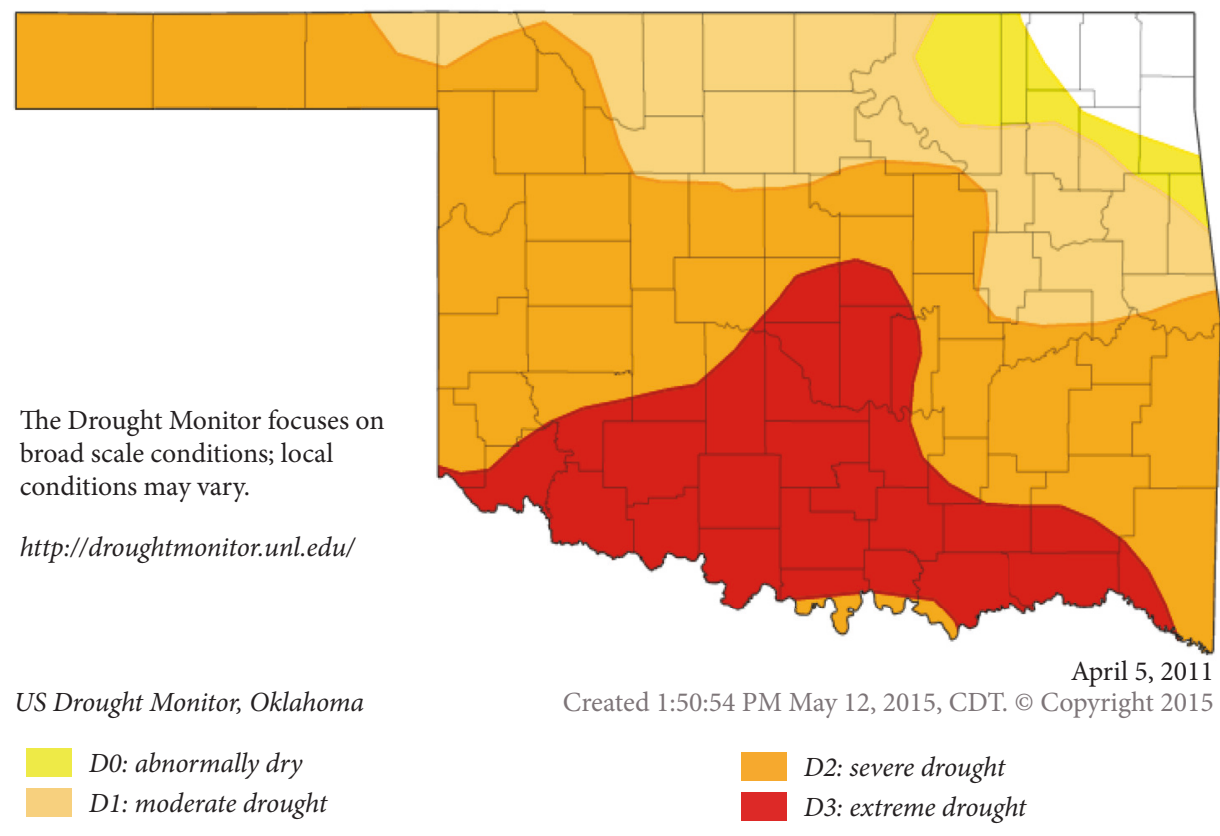

(a)

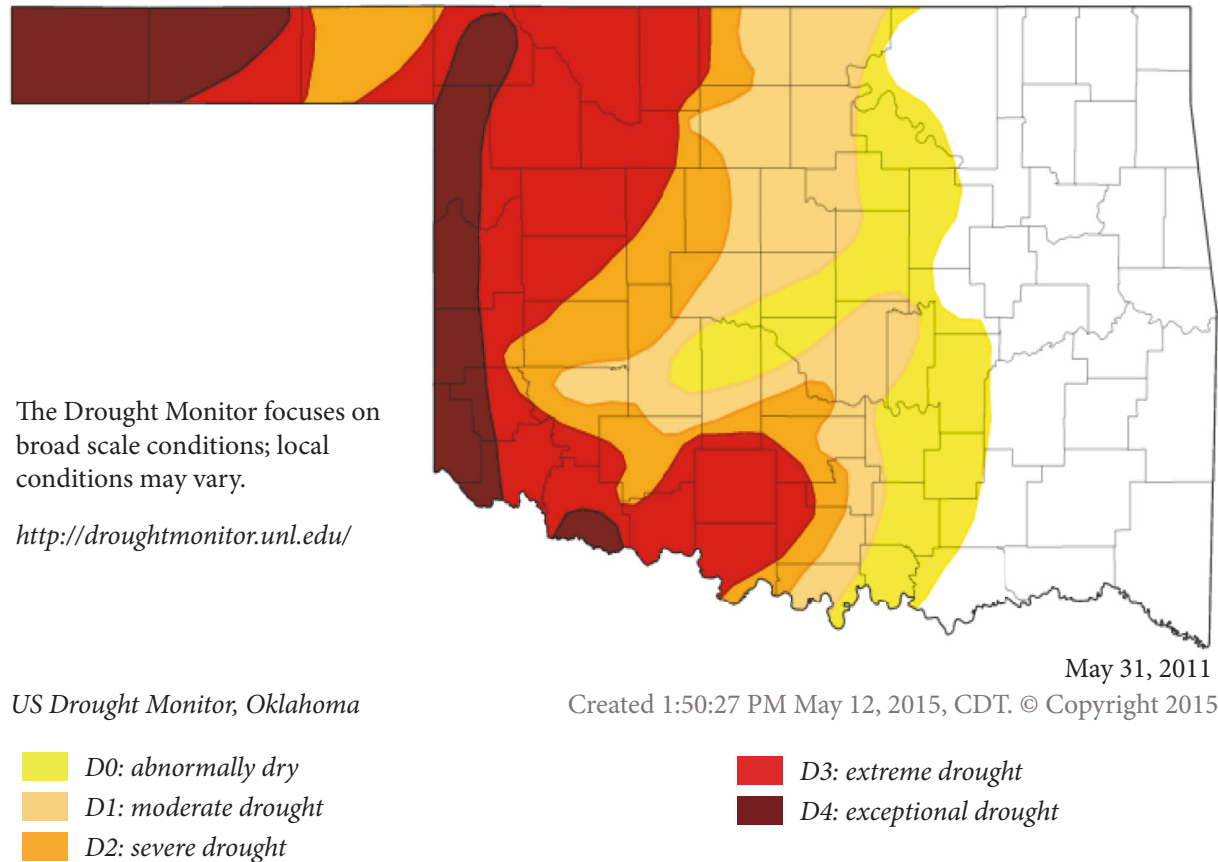

(b)

FIGURE 3: United States Drought Monitor plot showing the categorization of drought conditions on April 5 (a) and May 31 (b), 2011 (adapted from http://droughtmonitor.unl.edu/Home.aspx).

would increase evapotranspiration (ET) and thus decrease the effect the precipitation would have on soil moisture, along with increased surface runoff due to the excessive amounts of rainfall. In May, a different pattern emerged, with $5 \mathrm{~cm}$ FWI anomalies above normal over central and eastern Oklahoma while remaining below normal in western Oklahoma. While large areas of positive anomalies in central and eastern Oklahoma were due to the above average precipitation, areas of positive $5 \mathrm{~cm}$ FWI anomalies in central Oklahoma cannot be attributed to above average rainfall. This likely shows 


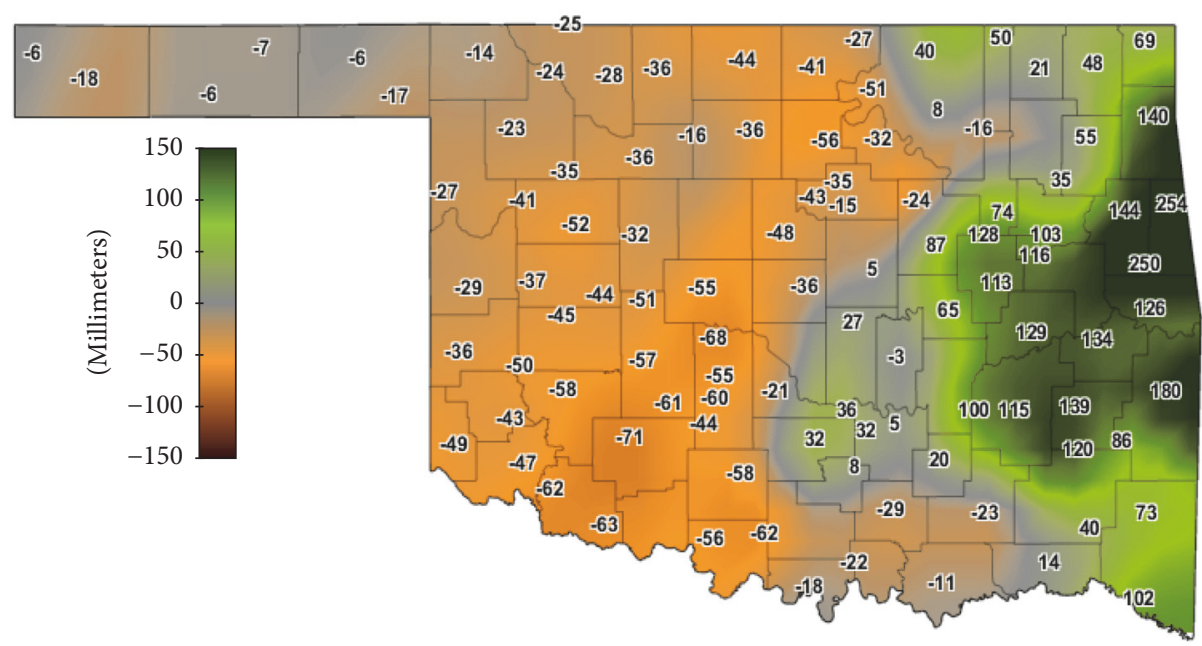

Total rainfall with estimates

Deviation from 1999-2014 average, April 2011 Created 3:56:47 PM July 27, 2015, UTC. () Copyright 2015

(a)

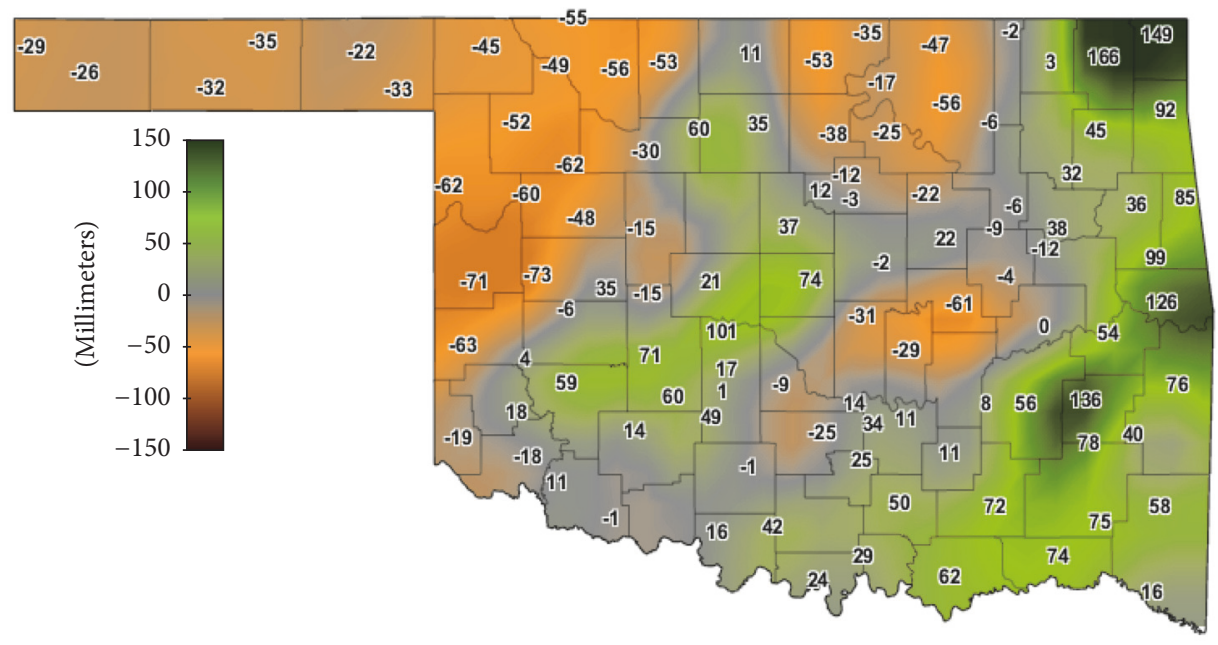

Total rainfall with estimates

Deviation from 1999-2014 average, May 2011 Created 3:56:50 PM July 27, 2015, UTC. () Copyright 2015

(b)

FIGURE 4: Map showing the monthly deviations from average total rainfall over the state of Oklahoma for April (a) and May (b) 2011, using measurements obtained from the Oklahoma Mesonet. Values display the actual deviation at each station and color filled gradient was created using a four-pass Barnes technique using the values at each station. Deviations are calculated from the 1999-2014 average during each month.

that precipitation was percolating deeper into the soil more effectively than would occur during a typical month. This could be due to different soil characteristics in this area or by decreased evaporation in this region of lower rainfall anomalies. With lower surface temperatures in this portion of the state at the time it can be seen that evapotranspiration would be reduced and thus soil moisture values would be increased. While soil moisture observations are collected at 5,25 , and $60 \mathrm{~cm}$, only the $5 \mathrm{~cm}$ FWI anomalies were included due to analysis of the other depths showing similar trends during these two months.

3.2. Dry Line Analysis. From March to August a total of 36 dry lines were analyzed with four occurring in March, six in April, seventeen in May, eight in June, zero in July, and one in August. The approximate location of each of these dry lines is shown in Figure 8. This figure indicates two areas of preferred dry line locations, over the central to west central portion of the state and in the northwest portion of the state into the panhandle. Coffer et al. [61] mentioned in their analysis of model dry line position errors that 2011 was an active year with frequent passages of shortwave troughs across the central Plains. Hane [62] states that dry lines that form in active synoptic regimes propagate further to the east during the day than those that develop during quiescent periods because the increased westerly momentum associated with the synoptic disturbance aids the vertical turbulent mixing in shifting the boundary towards the east. 


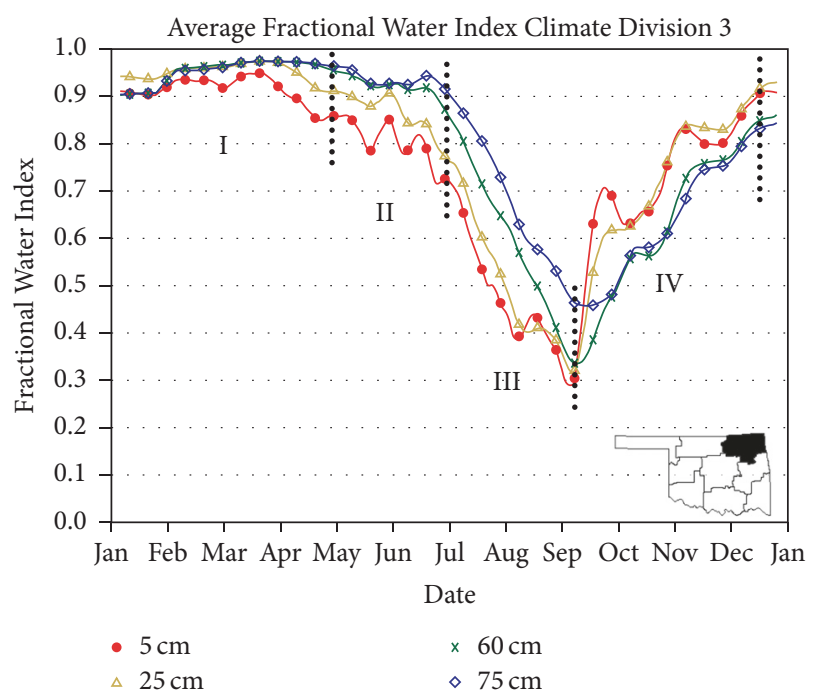

(a)

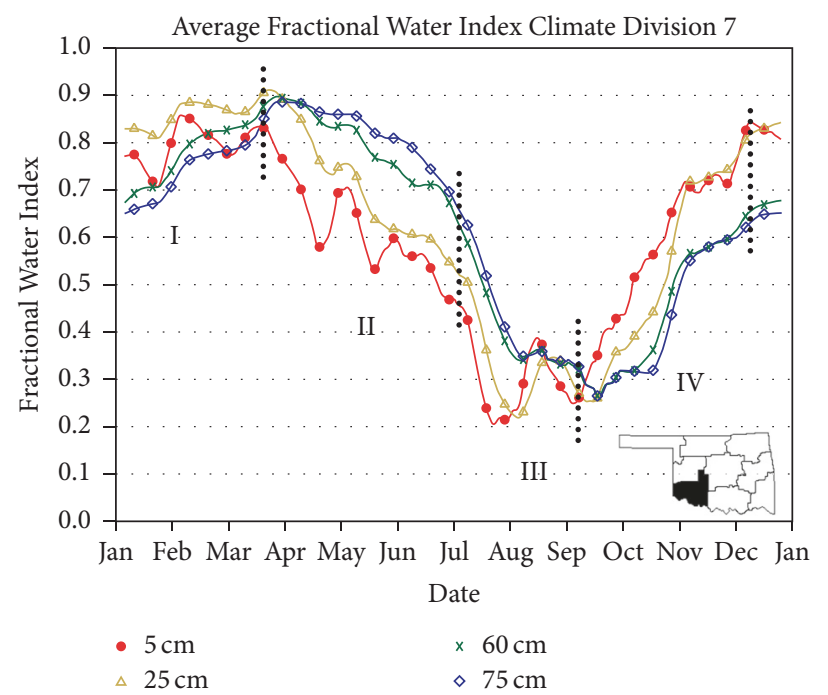

(b)

FIGURE 5: The average FWI trend for two different climate divisions in Oklahoma. The right plot is for the Southwest Climate division and the left plot is for the Northeast Climate Division (shown in the bottom right corner of each plot). The roman numerals on the plot represent the moist plateau phase (I: November to mid-March), the transitional drying phase (II: mid-March to mid-June), enhanced drying phase (III: mid-June to late August), and the recharge phase (IV: late August to November). Adapted from Illston et al. [40].

While it is difficult to remove the influence of the synoptic pattern on dry line location, a distinction between dry line synoptic classifications can be made in order to gain better understanding of the influence the drought had on dry line location.

Results of this analysis are shown in Table 2. The results revealed that the average dry line position was $2.5^{\circ}\left(2.4^{\circ}\right)$ longitude further to the east during April (May) when compared to climatology. Even with this eastward shift in the dry line, the overall seasonal progression of the average dry line location towards the west was similar to climatology. Linear trend analyses for each type of dry line show that dry lines with or without precipitation transitioned towards the west through the 3-month period, while dry lines with $\mathrm{CI}$ and no precipitation did not exhibit any discernable shift in average longitude through the season. With respect to differing dry line synoptic classifications, active dry lines were on average located further to the west than quiescent dry lines at 0000 UTC (Table 2). During April, active dry lines were on average located at $97.7^{\circ} \mathrm{W}$ while quiescent dry lines were located at $96.9^{\circ} \mathrm{W}$. This trend continued into May with the active dry lines average longitude at $99.0^{\circ} \mathrm{W}$ and the quiescent dry lines at $98.3^{\circ} \mathrm{W}$. This is counter to Hane [62] which mentions that active dry lines propagate further to the east than quiescent dry lines during the daily cycle. These results were not expected, as propagation of synoptically active dry lines is due to surface conditions and the synoptic flow pattern, with propagation of quiescent dry lines due to surface conditions alone. However, with synoptically active dry lines being influenced by the frontal boundary trailing beyond the moisture gradient these boundaries would have a finite distance they could propagate before being overtaken by the surface front, while quiescent dry lines would not have that limitation. Thus, with surface conditions conducive to more rapid eastward propagation when compared to normal, it would not be unexpected to see quiescent dry lines at 0000 UTC being further to the east on average compared to synoptically active dry lines.

To determine if land-atmosphere interactions played a role in dry line CI, average longitudes of dry lines with and without coincident precipitation were compared. Through modification of the prestorm environment, surface conditions have a large influence on whether CI can occur. Ford et al. [63] found that storms over Oklahoma preferentially initiate over drier soils compared with wet soils but further mentioned that storm initiation is not determined solely by soil moisture as storms were analyzed to initiate above wetter soils as well. Recalling the "dry and wet" pattern displayed in the observations (Figures 4 and 7), dry lines located further to the east would be located closer to areas in which soils were wetter than average. With dry lines being closer to these wetter areas their results would suggest that CI would be less likely to occur. However, a wetter than average soil also allows for higher convective available potential energy (CAPE) due to increased low-level moisture along with a decrease in convective inhibition (CIN), the level of free convection (LFC), and surface temperature [63]. Thus, while the potential for deep convection is increased due to higher CAPE, lower CIN, and a lower LFC, the potential for deep convection is also limited because surface convective forcing is diminished when surface temperatures decrease over wetter soils due to enhanced evapotranspiration.

The average dry line longitudes for precipitating dry lines indicate that this "dry and wet" pattern influenced dry line CI. Average dry lines that produced precipitation during April and May were approximately $1.5^{\circ}$ (1.5 and $1.4^{\circ}$, resp.) 


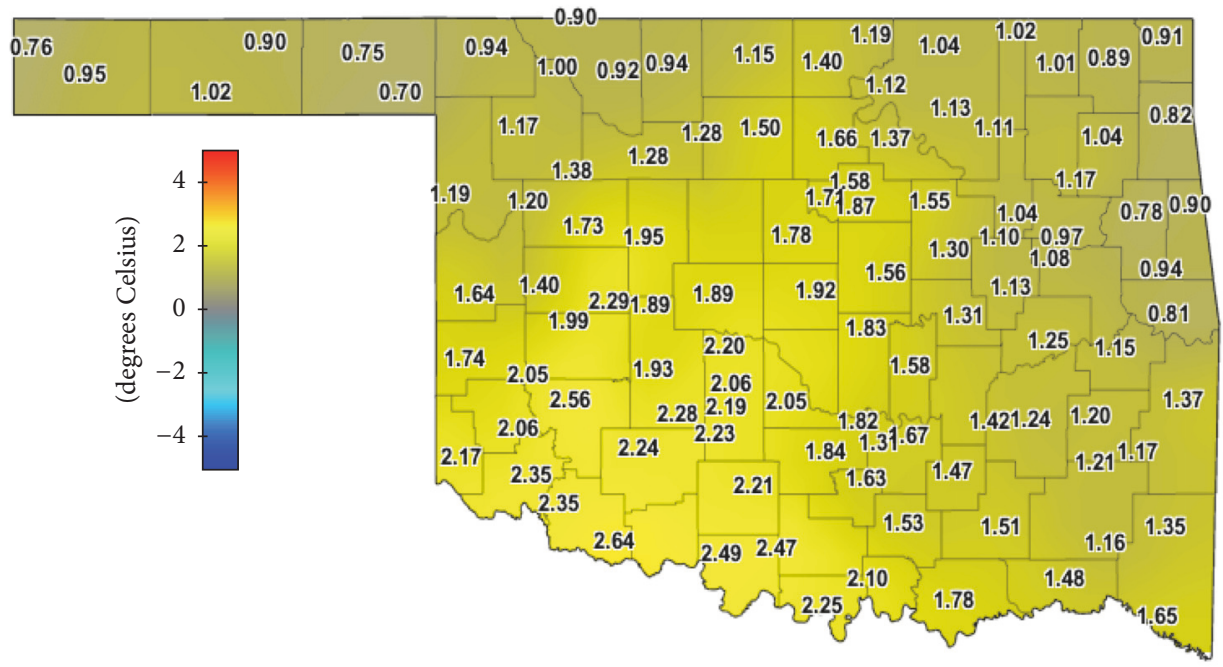

Average air temperature

Deviation from 1999-2014 average, April 2011 Created 3:56:48 PM July 27, 2015, UTC. (C) Copyright 2015

(a)

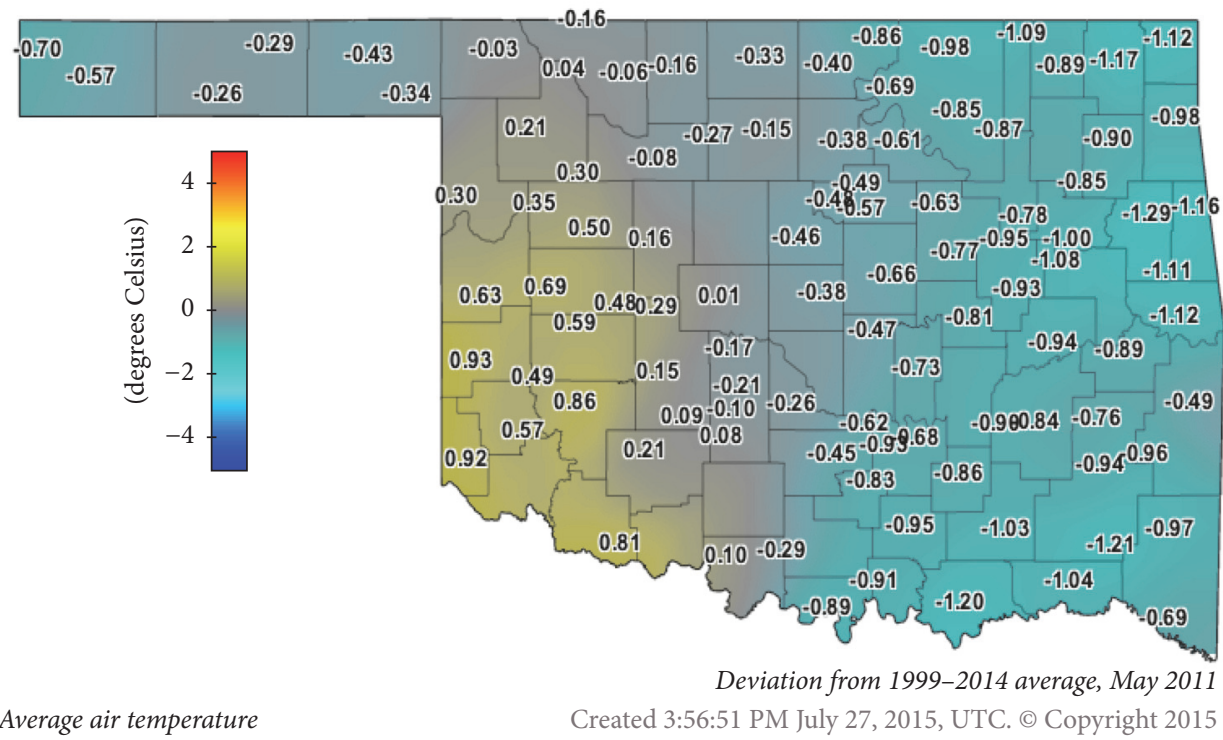

(b)

FIgURE 6: Same as Figure 4, except for average air temperature.

longitude further to the east than dry lines that produced CI but did not produce precipitation at any Mesonet Stations. However, analysis on the longitude of CI and precipitation due to the dry line boundaries tends to disagree. Average longitudes for dry line produced CI (April 98.6 ${ }^{\circ} \mathrm{W}$; May $99.3^{\circ} \mathrm{W}$ ) were further to the west than the average dry line longitude (April $97.3^{\circ} \mathrm{W}$; May $98.6^{\circ} \mathrm{W}$ ). This shows that CI that occurred due to the dry line boundaries originated behind the dry line boundaries and thus was unlikely to be directly caused by the surface conditions gradient owing to the "dry and wet" pattern. Dry line produced precipitation, however, agrees with the hypothesis that the pattern impacted the boundaries. Average rainfall longitudes were further to the east or at the monthly average dry line longitude. For April, dry line produced precipitation on average was at $97.5^{\circ} \mathrm{W}$ while during May this was at $98.1^{\circ} \mathrm{W}$. This appears to show that rainfall was on average behind the dry line in April, but this was an effect of the few number of precipitating dry lines in April and the manner in which rainfall longitude for each event was determined.

When taking into account synoptic influence, an important result is seen. During the month of May active dry lines $\left(99.0^{\circ} \mathrm{W}\right)$ were further to the west than quiescent dry lines $\left(98.3^{\circ} \mathrm{W}\right)$ on average (Table 2$)$. This indicates that even with synoptic forcing dry lines that were influenced by the surface alone developed and propagated further to the east. Precipitation from these dry lines was influenced as well, as rainfall that occurred from quiescent dry lines 


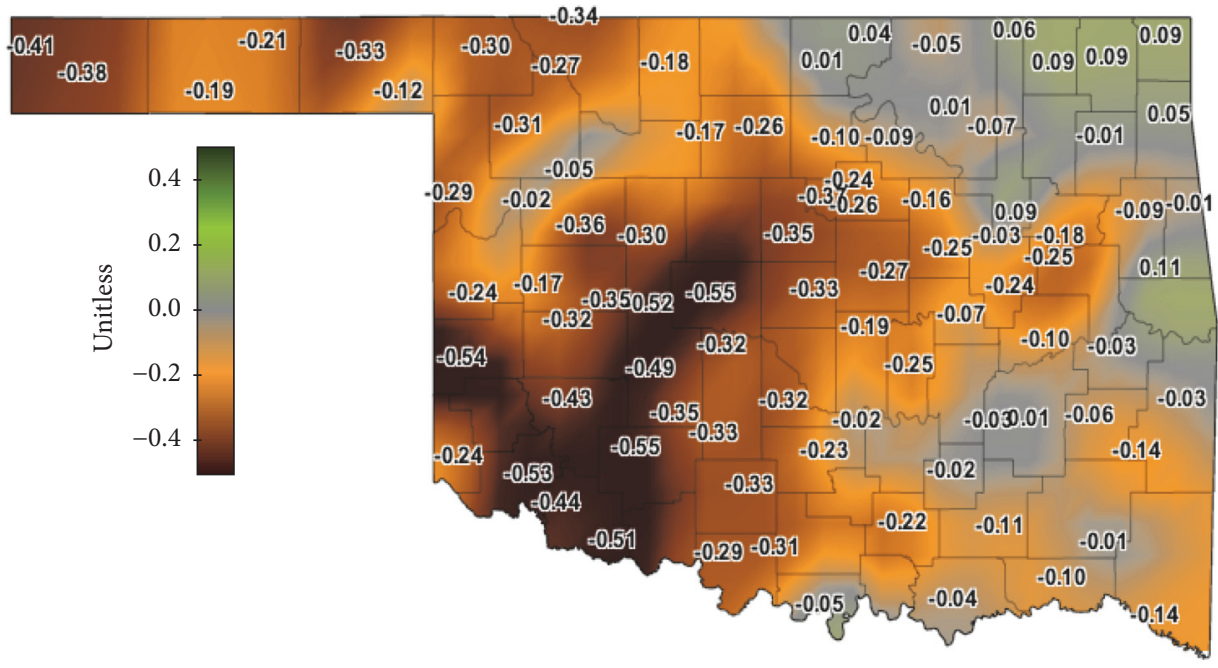

Deviation from 1999-2014 average, April 2011

Average 5-centimeter Fractional Water Index Created 3:56:46 PM July 27, 2015, UTC. @) Copyright 2015

(a)

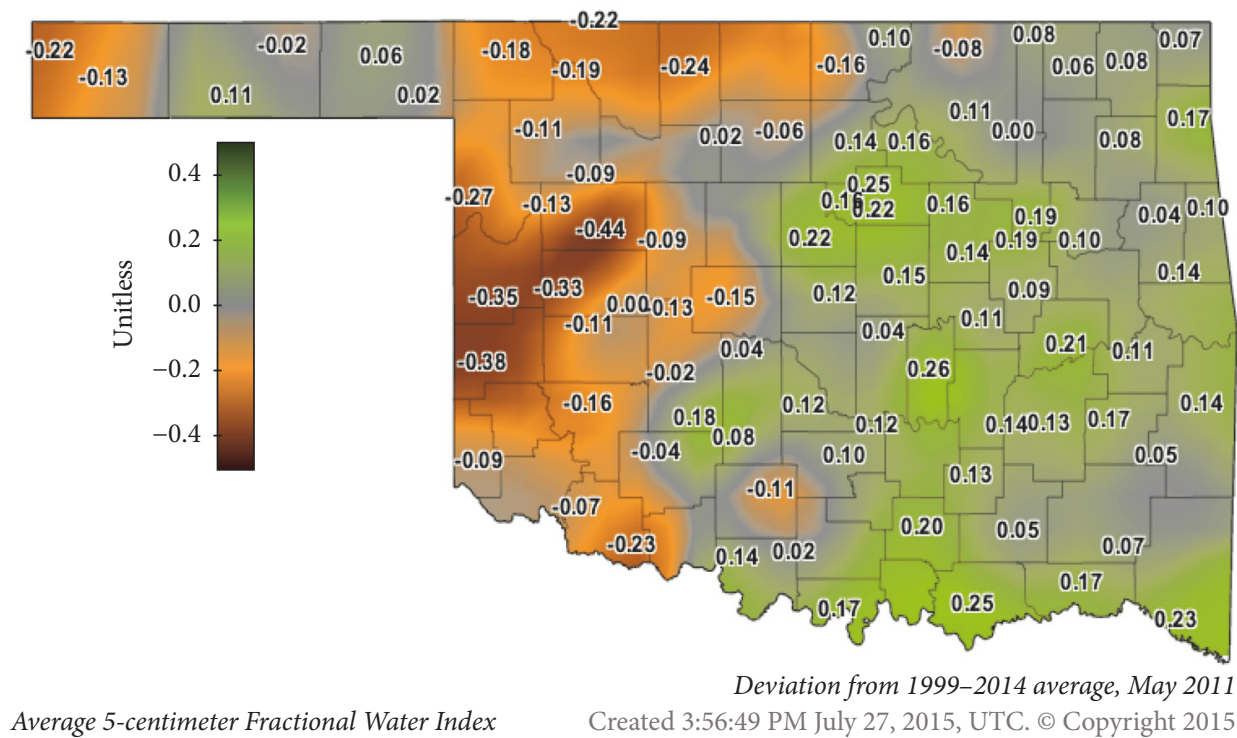

(b)

FIgURE 7: Same as Figure 4, except for $5 \mathrm{~cm}$ FWI.

was $1^{\circ}$ longitude further to the east than rainfall initiated by active dry lines. Conversely, during April, the "dry and wet" pattern originated due to anomalous rainfall caused by a large number of synoptic waves along with the few precipitating dry lines. Thus, the influence of the pattern would not have been significant during this month.

\section{WRF-ARW Modeling Case Studies and Sensitivity Simulations}

From observations, an apparent shift of the dry line boundary towards eastern Oklahoma was seen in conjunction with a soil moisture anomaly gradient over the central portion of the state. To quantify the effect of the soil moisture gradient on specific dry line cases during this season, simulations were completed using control and modified soil moisture fields. Using the WRF-ARW modeling system, four case studies were investigated, two from April (08 and 14 April) and two from May (08 and 21 May). To quantify the effect that the surface (i.e., soil moisture) had on the dry line boundary under varying synoptic conditions, two of these cases were synoptically forced (14 April and 21 May) while the other two occurred during quiescent periods (08 April and 08 May). Simulations using HRLDAS soil moisture values (Control) well represented each case with minor differences when compared to Mesonet observations. Dry line boundaries were shifted slightly to the east (in Control) compared to observations; however this is in line with a study 
TABLE 2: Overview of the dry line analysis statistics for the months of April and May. Included is the average monthly longitude for each category of dry line (CI no rain, rain, from climatology and from observations; degrees longitude), the average longitude of dry line CI and dry line rainfall, and the percent number of days having a dry line from observations. These statistics are also broken down for each month into quiescent and active dry line classifications. Dry lines included in this analysis are either from 0000 UTC, except for 1 dry line in April and 2 in May that were analyzed at 2100 UTC due to frontal influences at 0000 UTC.

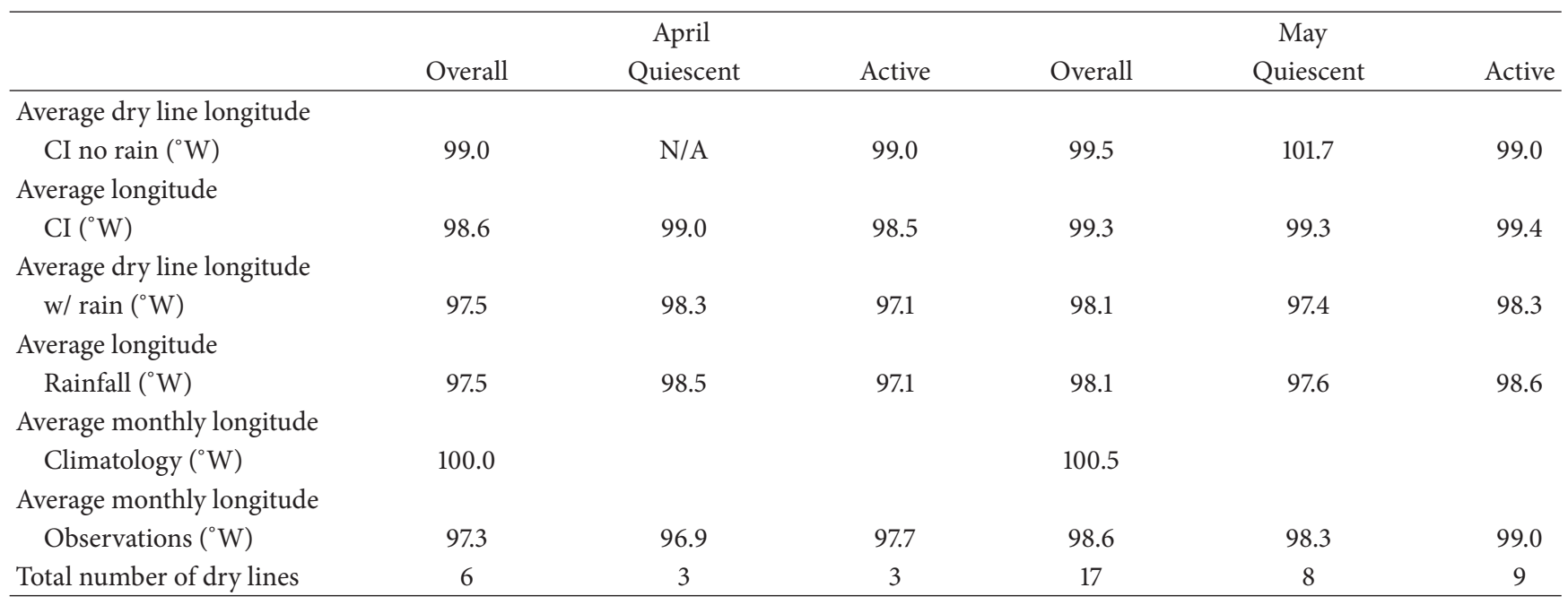

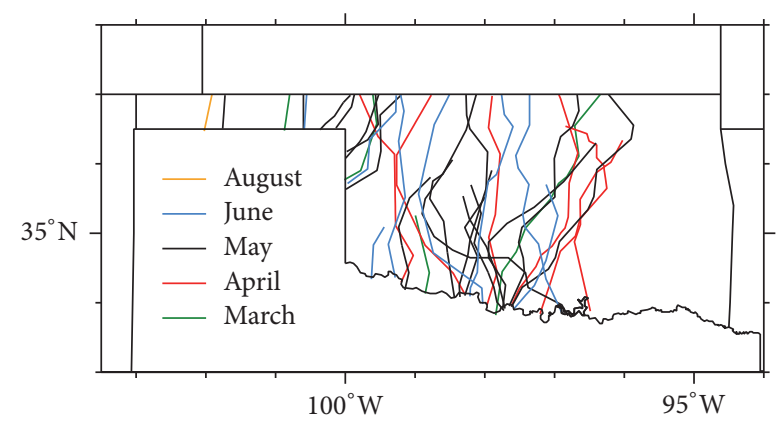

Figure 8: Analysis of all dry lines boundaries from March to August in 2011. Lines represent the dry line boundary as defined by the easternmost contour of specific humidity that was contained within the dry line moisture gradient.

by Coffer et al. [61] that found an eastward bias of the dry line in the operational NSSL-WRF system. Surface fields were also well represented by the Control simulations, with each simulation incurring small perturbations to the surface temperature and moisture fields. Simulated reflectivity and precipitation totals showed that the WRF-ARW was able to accurately depict the nature of each dry line event, from CI to the later portions of storm evolution.

Overall, modifying soil moisture in the WRF simulations had a definitive impact on dry line structure and subsequent CI. The Dry simulations were drier and warmer than the Control with a dry line that was shifted to the east (Figures $9,10,11$, and 12). The PBL produced in a Dry simulation was typically deeper than the Control and much drier while CI would occur earlier in time than in the Control simulations. For the Moist simulations, the surface moisture was greater with cooler surface temperatures. The dry line boundary was typically shifted to the west (Figures 9, 10, 11, and 12), and

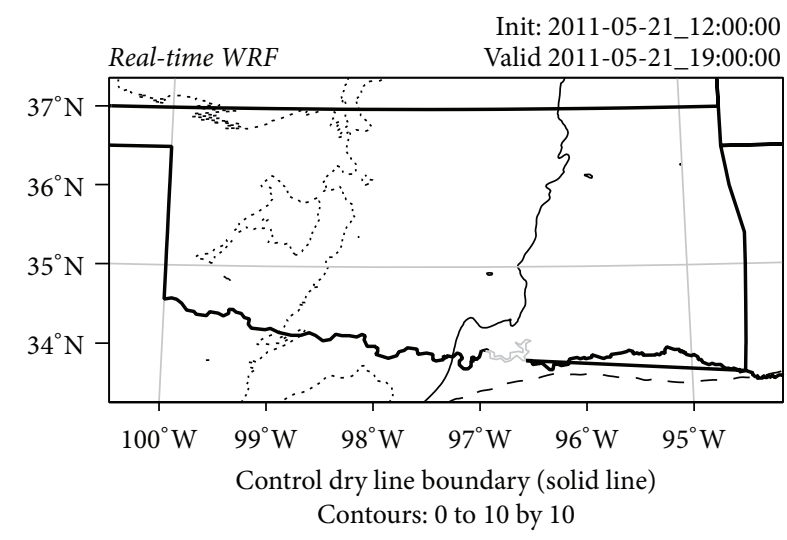

Moist dry line boundary (short dash) $(\mathrm{g} / \mathrm{kg})$ Dry dry line boundary (long dash) $(\mathrm{g} / \mathrm{kg})$ Control dry line boundary (solid line) $(\mathrm{g} / \mathrm{kg})$

FIGURE 9: Plot showing the proxy dry line boundary for the May 21 simulations. The solid black line represents the Control dry line, the short dash black line the Moist dry line, and the long dash black line the Dry dry line at 1900 UTC. The specific contour was chosen to best represent the Control dry line boundary structure at the surface.

like the Dry cases more diffuse than Control. Further, the PBL depth was shallower, with more moisture within the layer which further produced lower LCL heights. Of note, the depth of the PBL with relation to LCL heights appeared to play a significant role in determining whether CI occurred (April 8, May 8, and May 21 Moist simulations), along with the effect the cooler near-surface temperatures would have in stabilizing the environment.

Because the focus of this modeling study was to quantify the impact of the existing soil moisture regime ("dry and wet" regime) on the dry line boundary, the location of the 


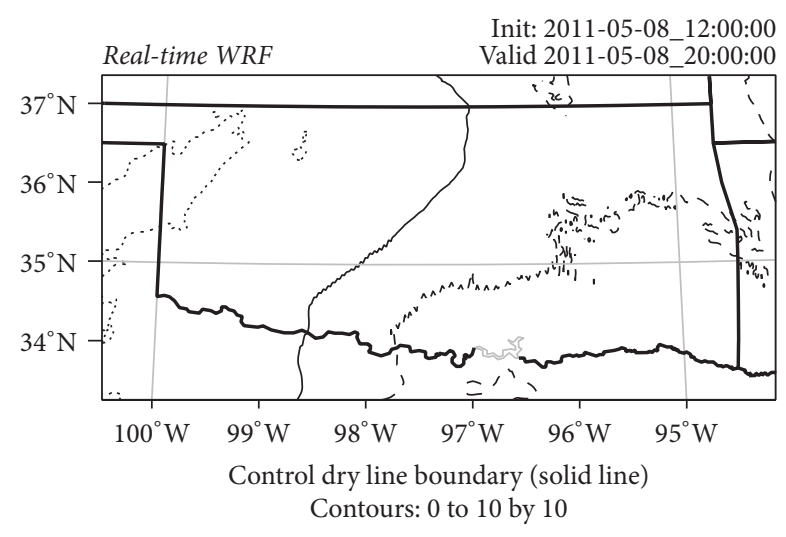

Moist dry line boundary (short dash) $(\mathrm{g} / \mathrm{kg})$

Dry dry line boundary (long dash) $(\mathrm{g} / \mathrm{kg})$

Control dry line boundary (solid line) $(\mathrm{g} / \mathrm{kg})$

FIGURE 10: Same as Figure 9, except for the May 8 simulation at 2000 UTC.

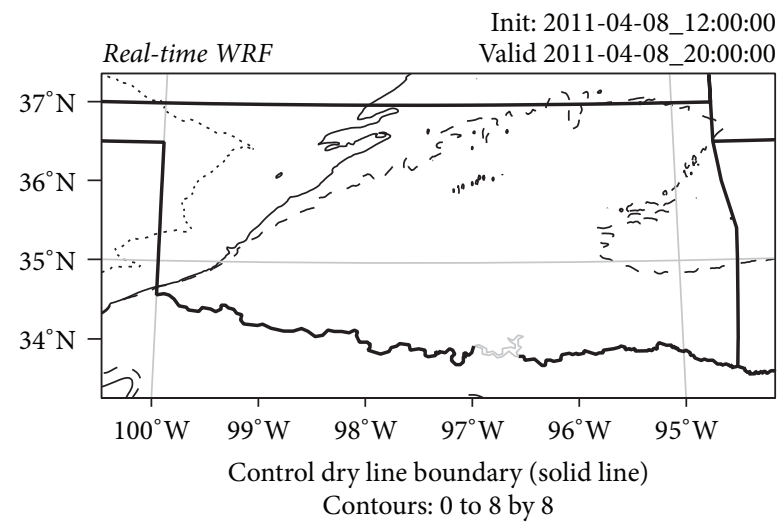

Moist dry line boundary (short dash) $(\mathrm{g} / \mathrm{kg})$

Dry dry line boundary (long dash) $(\mathrm{g} / \mathrm{kg})$

Control dry line boundary (solid line) $(\mathrm{g} / \mathrm{kg})$

FIGURE 11: Same as Figure 9, except for the April 8 simulation at 2000 UTC. Control dry line proxy contour is the $8 \mathrm{~g} \mathrm{~kg}^{-1}$ contour.

dry line boundary was the primary focus within the case studies. The modification of soil moisture to the May dry line cases (Figures 9 and 10) produced more significant changes to the dry line boundary than the same changes made to the April dry line cases (Figures 11 and 12). The removal of soil moisture on the May 21 dry line event removed the dry line boundary and changed the nature of the event altogether. This can be seen in Figure 9 as the Dry simulation proxy dry line boundary $(10 \mathrm{~g} / \mathrm{kg}$ specific humidity contour; value chosen because this contour well represented the dry line boundary in the Control simulation) was shifted nearly outside of the domain. Adding soil moisture over the domain in the May 21 dry line case caused a large shift in the dry line boundary towards the west (Figure 9). The addition of soil moisture to the May 8 dry line case shifted the dry line from central Oklahoma to the Oklahoma/Texas panhandle border (Figure 10). Further, the addition of soil moisture in this case caused a large increase in atmospheric moisture

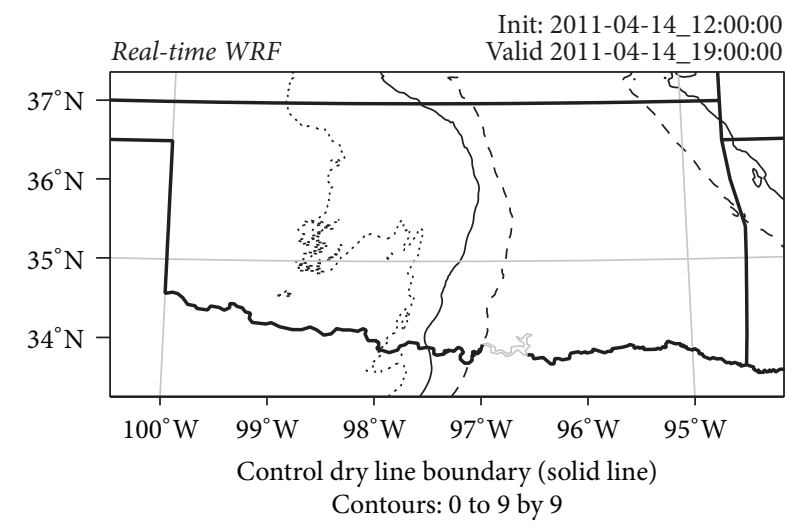

Moist dry line boundary (short dash) $(\mathrm{g} / \mathrm{kg})$ Dry dry line boundary (long dash) $(\mathrm{g} / \mathrm{kg})$ Control dry line boundary (solid line) $(\mathrm{g} / \mathrm{kg})$

FIgure 12: Same as Figure 9, except for the April 14 simulation at 1900 UTC. Control dry line proxy contour is the $9 \mathrm{~g} \mathrm{~kg}^{-1}$ contour.

in the PBL over western Oklahoma that was not seen in Control as soil moisture conditions were particularly dry over western Oklahoma at that time. The removal of soil moisture on the May 8 dry line was also significant. The structure of the surface moisture gradient was similar to that of Control; however drying caused the shifting of this gradient towards lower values of specific humidity and hence the difference seen in Figure 10. The changes to the PBL were typical for a Dry simulation, with an increase of PBL height and overall being drier than the Moist simulation. In the April 08 and April 14 simulations (Figures 11 and 12), these shifts in the dry line boundary and the changes in structure noted in the May simulations did not occur. The modifications to soil moisture did have an impact on dry line location and structure in the April 08 simulation (Figure 11), an expected result given that it was a quiescent dry line. However, the impacts were not as significant as with the May 08 dry line simulations, the other simulated quiescent dry line. The April 14 simulated dry line boundary did incur shifts to the east (DRY) and west (MOIST); however they did not change the surface structure of the dry line boundary (Figure 12). These results show that land-atmosphere interactions were more impactful on May dry lines (Figures 9 and 10) than on April dry lines (Figures 11 and 12) within our WRF simulations. While synoptic influences on dry line location and evolution were similar in April and May, the impact the surface imparted on dry line cases during May was increased compared to the influences the surface had on the April dry lines.

\section{Discussion and Conclusions}

This study was completed to investigate the role of the dry line in the evolution of the drought over Oklahoma during 2011. An analysis of in situ observations from the Oklahoma Mesonet provided background knowledge into the drought intensity and evolution along with dry line characteristics during the period. Using the observations, a criteria based dry line identification method was designed similar to that of 
the Hoch and Markowski [43] dry line identification method to develop a dataset of dry line statistics. Lastly, a modeling study using the WRF system was used to quantify the impact of soil conditions on the dry line in select cases with the goal of determining the effect of varying soil conditions on the dry line during 2011 and modifications to the dry line pattern and subsequent precipitation.

Analysis of Mesonet observations during the period provided several key results about the evolution of the 2011 drought. During the spring, conditions were ideal for drought to progress from southern Oklahoma into the northern portions of the state yet during April precipitation (Figure 4(a)) in eastern Oklahoma eased drought conditions. $\mathrm{Su}$ and Dickinson [60] found that synoptic conditions were favorable for CI to occur in eastern Oklahoma while being inhibited in western Oklahoma during the month of April. Further, during May, conditions were such that drought did not progress in eastern Oklahoma due to below normal temperatures (Figure 6(b)) and above normal precipitation (Figure 4(b)). This anomalous precipitation during May in eastern and portions of west central Oklahoma was partially due to dry line events ( 8 out of 17 rainfall events). However, in western Oklahoma extreme drought continued to intensify during April and May (Figure 4). As such, the intensification of drought in eastern Oklahoma was delayed from April to June while across western Oklahoma drought continued to intensify and subsequently produced a "dry and wet" pattern (dry in the west, wet in the east) during this period.

Given the "dry and wet" pattern, the role of the surface conditions due, in part to drought, on dry line development was investigated. Using the Hoch and Markowski [43] dry line climatology for comparison, results demonstrated that average dry line longitudes during the period were anomalously located towards the east (Table 2); average monthly dry line longitudes typically occur near $100^{\circ} \mathrm{W}$, while during 2011 the investigation showed that average monthly dry line longitudes were near $98^{\circ} \mathrm{W}$. Analysis of CI showed that dry lines in April and May which produced precipitating storms were located further to the east than dry lines that did not initiate any storms with precipitation. Thus, the dry line was influenced by the "dry and wet" pattern with a mean position located near the gradient between drought and nondrought conditions. The mean location of the numerous (6 during April, 17 during May) dry line events would modify surface conditions owing to the atmospheric pattern that defines a dry line event. West of these dry lines a drier air mass would be conducive for higher temperatures, enhanced ET, and greater overall atmospheric demand thus enhancing the existing drought conditions in these areas. Conversely, to the east of these boundaries enhanced moisture advection from the south and reduced vapor pressure deficit inhibited ET and limited drought development. Additionally, convective precipitation that develops along the dry line boundary propagates eastward and further limits drought development in this portion of the "dry and wet" pattern. As such, the results of this study show that there was a likely enhancement of the "dry and wet" pattern over central Oklahoma owing to the numerous dry line events that occurred within the month of May and the subsequent precipitation/ET pattern that these events caused.

Separating dry lines into synoptic classifications revealed an important result: synoptically active dry lines were on average further to the west than quiescent dry lines. This is especially true for the month of May in which quiescent dry lines that produced precipitation (as well as the associated precipitation and CI longitudes) were all further to the east when compared to active dry lines. As such, the more eastward placement of quiescent precipitating dry lines is important due to the fact that quiescent dry lines are more susceptible to surface conditions given that surface fluxes are the main driver for the turbulent mixing that propagate dry lines eastward [62]. Thus, these results show that surface conditions were impacting dry line position. It appears that when synoptic patterns influenced dry line boundaries during May that propagation towards the east was hindered compared to when surface conditions were the main driver of dry line evolution.

With dry line positions being much further to the east than the climatological normal, the meteorological patterns that are associated with these features would also be shifted towards the east. This would drive precipitation patterns associated with the dry line further to the east, along with the influences of the dry air mass that forms behind the dry line. Thus, the features impact surface conditions in such a way that would strengthen the "dry and wet" pattern over the state, as the dry air mass would continue to dry out the western extent of the state, while the moist air mass to the east would continue to provide the eastern portions of the state with lower temperatures, less surface evaporation, and a higher chance of deep convection and precipitation. As such, the pattern of drought that developed during late April and May was likely influenced by atmospheric conditions that developed due to the large number of dry line boundaries which were further to the east than the climatological normal.

A numerical modeling study into the effects of soil moisture conditions on specific dry line cases during the 2011 period was completed and four cases were chosen: two quiescent dry lines (April 8 and May 8) and two active dry lines of varying synoptic forcing strength (strongly forced April 14 and weakly forced May 21). The Control simulations demonstrated that the WRF produced reasonable atmospheric moisture gradients and precipitation patterns compared to observations. While differences were noted, these were typical to the WRF modeling system shown by previous studies [61]. Sensitivity simulations modifying soil moisture were completed to quantify the impacts of soil moisture on the dry line location during the study period. Results showed that during April these modifications led to typical results, with the addition or removal of soil moisture modifying the dry line events in such a way that did not influence the overall event that was simulated in the Control simulations. However, during May this was not the case. The modification of soil moisture in the WRF simulations led to changes compared to their Control simulations (Figures 9, 10, 11, and 12). In the Dry (Moist) simulation the dry line was shifted to the east (west) and had a different structure than that observed in Control. Thus, land-atmosphere interactions 
impacting dry line evolution were more significant during the month of May (Figures 9 and 10) than during April (Figures 11 and 12) within our WRF simulations. These extreme cases and the lack of such results from the April dry line simulations show there is a clear difference between the interactions between the dry line and surface conditions during these two months. Thus, the results show that if a different soil moisture pattern would have developed during April, then the May dry line would have had a different influence on the overall drought development. Shifting the dry line back towards the climatological normal $\left(\sim 100^{\circ} \mathrm{W}\right)$ would have shifted the moist air mass back towards the west and allowed for a higher chance of rainfall in the western extent of Oklahoma and aided in drought recovery, while shifting the dry line to the east would have reduced the rainfall over the entire state and would have aided in the development of the drought further to the east. However, the extent that drying over the entire state would impact overall dry line position is a difficult question in and of itself, as dry lines cannot propagate indefinitely to the east given extremely dry soil conditions over the entire region.

Overall the results show that surface conditions which developed during April 2011 affected dry line evolution during May. Because the dry line impacted precipitation development on the moist side of the wet-dry pattern, it further influenced the evolution of the drought during the months of April and May by abating the evolution of drought towards eastern Oklahoma until later in the warm season. These results provide evidence to a drought feedback process over the SGP. Surface processes begin to dry out soils through enhanced ET which leads to soil moisture anomalies which then influence the propagation of future dry line boundaries that can further strengthen or modify existing soil moisture anomalies through CI and precipitation. Thus, the evolution of surface conditions can enhance surface boundaries that cause the enhancement or modification of established surface anomalies (drought conditions). Future work should investigate this possible feedback loop further, using different drought cases during different years. Understanding of these processes could aid in the forecast of rapid drought evolution within the SGP, a result similarly noted in Otkin et al. [19].

Finally, it is important to note that numerous simulations were completed to determine the final configuration used in the numerical analyses. However, varying initial conditions and model configurations may lead to varying final results and possibly different overall conclusions. Future analyses are needed to determine the overall sensitivity of the dry line to varying drought evolution scenarios. While only a few modeling cases were shown, the cases were representative of the broader overall conditions during the period. Thus, the results increased the overall understanding of the dry line to rapidly varying surface conditions while further pointing to the need for further investigation across multiple drought years and large-scale environments driving the variability of surface conditions. Further, because in situ observations from the Mesonet were used to identify the dry line boundaries, cases that occurred outside of Oklahoma were not included. Even so, the numerous cases identified, and above average number of dry line events compared to the Hoch and
Markowski [43] climatology, show that such a limitation was minor as the climatological numbers found in Hoch and Markowski [43] include dry lines that occurred over the entire SGP region.

\section{Conflicts of Interest}

The authors declare that there are no conflicts of interest regarding the publication of this paper.

\section{Acknowledgments}

This work was supported, in part, by the NOAA Climate Program Office's Sectoral Applications Research Program (SARP) Grant NA13OAR4310122 and the Agriculture and Food Research Initiative Competitive Grant 2012-02355 from the USDA National Institute of Food and Agriculture (Grant nos. 2013-69002-23146 and 2016-68002-24967). Some of the computing for this project was performed at the OU Supercomputing Center for Education \& Research (OSCER) at the University of Oklahoma (OU). Oklahoma's taxpayers fund the Oklahoma Mesonet through the Oklahoma State Regents for Higher Education and the Oklahoma Department of Public Safety. The U.S. Drought Monitor is jointly produced by the National Drought Mitigation Center at the University of Nebraska-Lincoln, the United States Department of Agriculture, and the National Oceanic and Atmospheric Administration, Map Courtesy of NDMC-UNL.

\section{References}

[1] J. B. Basara, J. N. Maybourn, C. M. Peirano et al., "Drought and associated impacts in the Great Plains of the United States-a review," International Journal of Geosciences, vol. 4, pp. 72-81, 2013.

[2] D. A. Wilhite, M. D. Svoboda, and M. J. Hayes, "Understanding the complex impacts of drought: a key to enhancing drought mitigation and preparedness," Water Resources Management, vol. 21, no. 5, pp. 763-774, 2007.

[3] S. Schubert, M. J. Suarez, P. J. Pegion, R. D. Koster, and J. T. Bacmeister, "Causes of long term drought in the U.S. Great Plains," Journal of Climate, vol. 17, no. 3, pp. 485-503, 2004.

[4] B. I. Cook, R. Seager, and R. L. Miller, "Atmospheric circulation anomalies during two persistent north american droughts: 1932-1939 and 1948-1957," Climate Dynamics, vol. 36, no. 11, pp. 2339-2355, 2011.

[5] D. J. Burnette and D. W. Stahle, "Historical perspective on the dust bowl drought in the central United States," Climatic Change, vol. 116, no. 3-4, pp. 479-494, 2013.

[6] K. E. Trenberth, G. W. Branstator, and P. A. Arkin, "Origins of the 1988 North American drought," Science, vol. 242, no. 4886, pp. 1640-1645, 1988.

[7] S. D. Schubert, M. J. Suarez, P. J. Pegion, R. D. Koster, and J. T. Bacmeister, "On the cause of the 1930s dust bowl," Science, vol. 303, no. 5665, pp. 1855-1859, 2004.

[8] S. Brönnimann, A. Stickler, T. Griesser et al., "Exceptional atmospheric circulation during the 'dust bowl', Geophysical Research Letters, vol. 36, no. 8, Article ID L08802, 2009.

[9] X. Dong, B. Xi, A. Kennedy et al., "Investigation of the 2006 drought and 2007 flood extremes at the Southern Great Plains 
through an integrative analysis of observations," Journal of Geophysical Research, vol. 116, no. D3, article D0324, 2011.

[10] R. Seager, Y. Kushnir, C. Herweijer, N. Naik, and J. Velez, "Modeling of tropical forcing of persistent droughts and pluvials over Western North America: 1856-2000," Journal of Climate, vol. 18, no. 19, pp. 4065-4088, 2005.

[11] B. I. Cook, R. L. Miller, and R. Seager, "Dust and sea surface temperature forcing of the 1930s 'dust bowl' drought," Geophysical Research Letters, vol. 35, no. 8, Article ID L08710, 2008.

[12] L. Meng and S. M. Quiring, "Observational relationship of sea surface temperatures and precedent soil moisture with summer precipitation in the U.S. Great Plains," International Journal of Climatology, vol. 30, no. 6, pp. 884-893, 2010.

[13] S. Nigam, B. Guan, and A. Ruiz-Barradas, "Key role of the Atlantic Multidecadal Oscillation in 20th century drought and wet periods over the Great Plains," Geophysical Research Letters, vol. 38, no. 16, Article ID L16713, 2011.

[14] M. C. Veres and Q. Hu, "AMO-forced regional processes affecting summertime precipitation variations in the central United States," Journal of Climate, vol. 26, no. 1, pp. 276-290, 2013.

[15] R. J. Burgman and Y. Jang, "Simulated U.S. drought response to interannual and decadal pacific SST variability," Journal of Climate, vol. 28, no. 12, pp. 4688-4705, 2015.

[16] S. Schubert and Coauthors., "Global meteorological drought: a synthesis of current understanding on SST drivers of precipitation deficits," Journal of Climate, vol. 29, no. 11, pp. 3989-4019, 2016.

[17] S.-Y. Hong and E. Kalnay, "Role of sea surface temperature and soil-moisture feedback in the 1998 Oklahoma-Texas drought," Nature, vol. 408, no. 6814, pp. 842-844, 2000.

[18] T. W. Ford and S. M. Quiring, "In situ soil moisture coupled with extreme temperatures: a study based on the Oklahoma mesonet," Geophysical Research Letters, vol. 41, no. 13, pp. 47274734, 2014.

[19] J. A. Otkin, M. C. Anderson, C. Hain, I. E. Mladenova, J. B. Basara, and M. Svoboda, "Examining rapid onset drought development using the thermal infrared-based evaporative stress index," Journal of Hydrometeorology, vol. 14, no. 4, pp. 1057-1074, 2013.

[20] J. A. Otkin, M. C. Anderson, C. Hain et al., "Assessing the evolution of soil moisture and vegetation conditions during the 2012 United States flash drought," Agricultural and Forest Meteorology, vol. 218-219, pp. 230-242, 2016.

[21] K. C. Mo and D. P. Lettenmaier, "Heat wave flash droughts in decline," Geophysical Research Letters, vol. 42, no. 8, pp. 28232829, 2015.

[22] J. B. Basara and K. C. Crawford, "Linear relationships between root-zone soil moisture and atmospheric processes in the planetary boundary layer," Journal of Geophysical Research Atmospheres, vol. 107, no. 15, pp. 1-18, 2002.

[23] J. A. Santanello Jr., C. D. Peters-Lidard, S. V. Kumar, C. Alonge, and W.-K. Tao, "A modeling and observational framework for diagnosing local land-atmosphere coupling on diurnal time scales," Journal of Hydrometeorology, vol. 10, no. 3, pp. 577-599, 2009.

[24] R. D. Koster, P. A. Dirmeyer, Z. C. Guo et al., "Regions of strong coupling between soil moisture and precipitation," Science, vol. 305, no. 5687, pp. 1138-1140, 2004.

[25] L. Alfieri, P. Claps, P. D’Odorico, F. Laio, and T. M. Over, "An analysis of the soil moisture feedback on convective and stratiform precipitation," Journal of Hydrometeorology, vol. 9, no. 2, pp. 280-291, 2008.

[26] J. D. Frye and T. L. Mote, "Convection initiation along soil moisture boundaries in the southern Great Plains," Monthly Weather Review, vol. 138, no. 4, pp. 1140-1151, 2010.

[27] Z. Guo and P. A. Dirmeyer, "Interannual variability of landatmosphere coupling strength," Journal of Hydrometeorology, vol. 14, no. 5, pp. 1636-1646, 2013.

[28] J. Owen, "A study of thunderstorm formation along dry lines," Journal of Applied Meteorology, vol. 5, no. 1, pp. 58-63, 1966.

[29] C. L. Ziegler and C. E. Hane, "An observational study of the dryline," Monthly Weather Review, vol. 121, no. 4, pp. 1134-1151, 1993.

[30] L. D. Grasso, "A numerical simulation of dryline sensitivity to soil moisture," Monthly Weather Review, vol.128, no. 8, pp. 28162834, 2000.

[31] C. L. Ziegler, W. J. Martin, R. A. Pielke, and R. L. Walko, "A modeling study of the dryline," Journal of the Atmospheric Sciences, vol. 52, no. 2, pp. 263-285, 1995.

[32] B. L. Shaw, R. A. Pielke, and C. L. Ziegler, "A three-dimensional numerical simulation of a Great Plains dryline," Monthly Weather Review, vol. 125, no. 7, pp. 1489-1506, 1997.

[33] M. Hoerling, A. Kumar, R. Dole et al., "Anatomy of an extreme event," Journal of Climate, vol. 26, no. 9, pp. 2811-2832, 2013.

[34] T. Tadesse, B. D. Wardlow, J. F. Brown et al., "Assessing the vegetation condition impacts of the 2011 drought across the U.S. southern great plains using the vegetation drought response index (VegDRI)," Journal of Applied Meteorology and Climatology, vol. 54, no. 1, pp. 153-169, 2015.

[35] F. V. Brock, K. C. Crawford, R. L. Elliott et al., "The Oklahoma mesonet: a technical overview," Journal of Atmospheric and Oceanic Technology, vol. 12, no. 1, pp. 5-19, 1995.

[36] R. A. McPherson, C. A. Fiebrich, K. C. Crawford et al., "Statewide monitoring of the mesoscale environment: a technical update on the Oklahoma Mesonet," Journal of Atmospheric and Oceanic Technology, vol. 24, no. 3, pp. 301-321, 2007.

[37] M. A. Shafer, C. A. Fiebrich, D. Arndt, S. E. Fredrickson, and T. W. Hughes, "Quality assurance procedures in the Oklahoma Mesonetwork," Journal of Atmospheric and Oceanic Technology, vol. 17, no. 4, pp. 474-494, 2000.

[38] B. G. Illston, J. B. Basara, D. K. Fisher et al., "Mesoscale monitoring of soil moisture across a statewide network," Journal of Atmospheric and Oceanic Technology, vol. 25, no. 2, pp. 167182, 2008.

[39] W. Wu, M. A. Geller, and R. E. Dickinson, "The response of soil moisture to long-term variability of precipitation," Journal of Hydrometeorology, vol. 3, no. 5, pp. 604-613, 2002.

[40] B. G. Illston, J. B. Basara, and K. C. Crawford, "Seasonal to interannual variations of soil moisture measured in Oklahoma," International Journal of Climatology, vol. 24, no. 15, pp. 18831896, 2004.

[41] J. B. Basara and T. M. Crawford, "Improved installation procedures for deep-layer soil moisture measurements," Journal of Atmospheric and Oceanic Technology, vol. 17, no. 6, pp. 879-884, 2000.

[42] J. A. Goff and S. Gratch, "Low pressure properties of water from -160 to 212 F," Transactions of the American Society of Heating and Ventilating Engineers, vol. 52, pp. 95-121, 1946.

[43] J. Hoch and P. Markowski, "A climatology of springtime dryline position in the U.S. Great Plains region," Journal of Climate, vol. 18, no. 12, pp. 2132-2137, 2005. 
[44] E. J. Mlawer, S. J. Taubman, P. D. Brown, M. J. Iacono, and S. A. Clough, "Radiative transfer for inhomogeneous atmospheres: RRTM, a validated correlated-k model for the longwave," Journal of Geophysical Research, vol. 102, no. D14, pp. 1666316682, 1997.

[45] J. Dudhia, "Numerical study of convection observed during the Winter Monsoon Experiment using a mesoscale twodimensional model," Journal of the Atmospheric Sciences, vol. 46, no. 20, pp. 3077-3107, 1989.

[46] S. Hong, Y. Noh, and J. Dudhia, "A new vertical diffusion package with an explicit treatment of entrainment processes," Monthly Weather Review, vol. 134, no. 9, pp. 2318-2341, 2006.

[47] J. A. Gibbs, E. Fedorovich, and A. M. J. Van Eijk, "Evaluating weather research and forecasting (WRF) model predictions of turbulent flow parameters in a dry convective boundary layer," Journal of Applied Meteorology and Climatology, vol. 50, no. 12, pp. 2429-2444, 2011.

[48] J. S. Kain, "The Kain-Fritsch convective parameterization: an update," Journal of Applied Meteorology, vol. 43, no. 1, pp. 170181, 2004.

[49] H. Morrison, G. Thompson, and V. Tatarskii, "Impact of cloud microphysics on the development of trailing stratiform precipitation in a simulated squall line: comparison of one- and two-moment schemes," Monthly Weather Review, vol. 137, no. 3, pp. 991-1007, 2009.

[50] K.-S. S. Lim and S.-Y. Hong, "Development of an effective double-moment cloud microphysics scheme with prognostic cloud condensation nuclei (CCN) for weather and climate models," Monthly Weather Review, vol. 138, no. 5, pp. 1587-1612, 2010.

[51] F. Chen, K. W. Manning, M. A. LeMone et al., "Description and evaluation of the characteristics of the NCAR high-resolution land data assimilation system," Journal of Applied Meteorology and Climatology, vol. 46, no. 6, pp. 694-713, 2007.

[52] F. Chen and J. Dudhia, "Coupling and advanced land surfacehydrology model with the Penn State-NCAR MM5 modeling system. Part I: model implementation and sensitivity;" Monthly Weather Review, vol. 129, no. 4, pp. 569-585, 2001.

[53] M. B. Ek, K. E. Mitchell, Y. Lin et al., "Implementation of Noah land surface model advances in the National Centers for Environmental Prediction operational mesoscale Eta model," Journal of Geophysical Research, vol. 108, no. D22, article 8851, 2003.

[54] L. Mahrt and M. Ek, "The influence of atmospheric stability on potential evaporation," Journal of Climate and Applied Meteorology, vol. 23, no. 2, pp. 222-234, 1984.

[55] H.-L. Pan and L. Mahrt, "Interaction between soil hydrology and boundary-layer development," Boundary-Layer Meteorology, vol. 38, no. 1-2, pp. 185-202, 1987.

[56] J. Noilhan and S. Planton, "A simple parameterization of land surface processes for meteorological models," Monthly Weather Review, vol. 117, no. 3, pp. 536-549, 1989.

[57] F. Chen, K. Mitchell, J. Schaake et al., "Modeling of land surface evaporation by four schemes and comparison with FIFE observations," Journal of Geophysical Research, vol. 101, no. 3, pp. 7251-7268, 1996.

[58] B. A. Cosgrove, "Land surface model spin-up behavior in the North American Land Data Assimilation System (NLDAS)," Journal of Geophysical Research, vol. 108, no. D22, 2003.

[59] B. L. Shaw, The effect of soil moisture and vegetation heterogeneity on a Great Plains dryline: a numerical study [M.S. thesis], Colorado State University, Fort Collins, Colo, USA, 1995.
[60] H. Su and R. E. Dickinson, "On the spatial gradient of soil moisture-precipitation feedback strength in the April 2011 drought in the Southern Great Plains," Journal of Climate, vol. 30, no. 3, pp. 829-848, 2017.

[61] B. E. Coffer, L. C. Maudlin, P. G. Veals, and A. J. Clark, "Dryline position errors in experimental convection-allowing NSSLWRF model forecasts and the operational NAM," Weather and Forecasting, vol. 28, no. 3, pp. 746-761, 2013.

[62] C. E. Hane, "Quiescent and synoptically-active drylines: a comparison based upon case studies," Meteorology and Atmospheric Physics, vol. 86, no. 3-4, pp. 195-211, 2004.

[63] T. W. Ford, A. D. Rapp, S. M. Quiring, and J. Blake, "Soil moisture-precipitation coupling: observations from the Oklahoma Mesonet and underlying physical mechanisms," Hydrology and Earth System Sciences Discussions, vol. 12, pp. 32053243, 2015. 

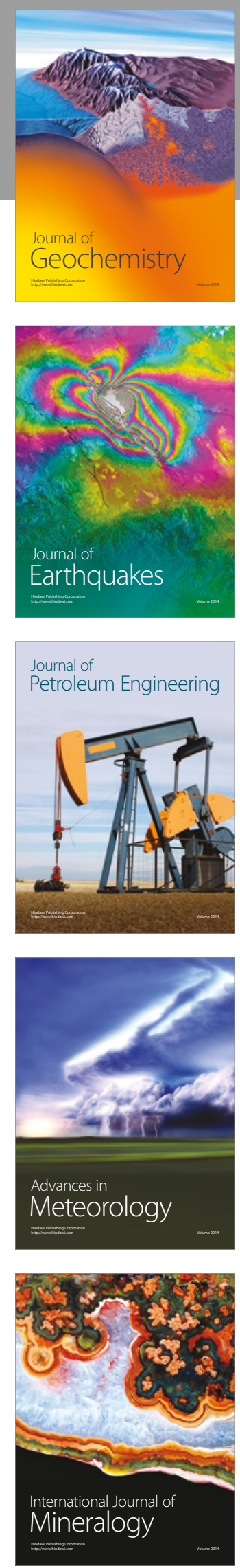
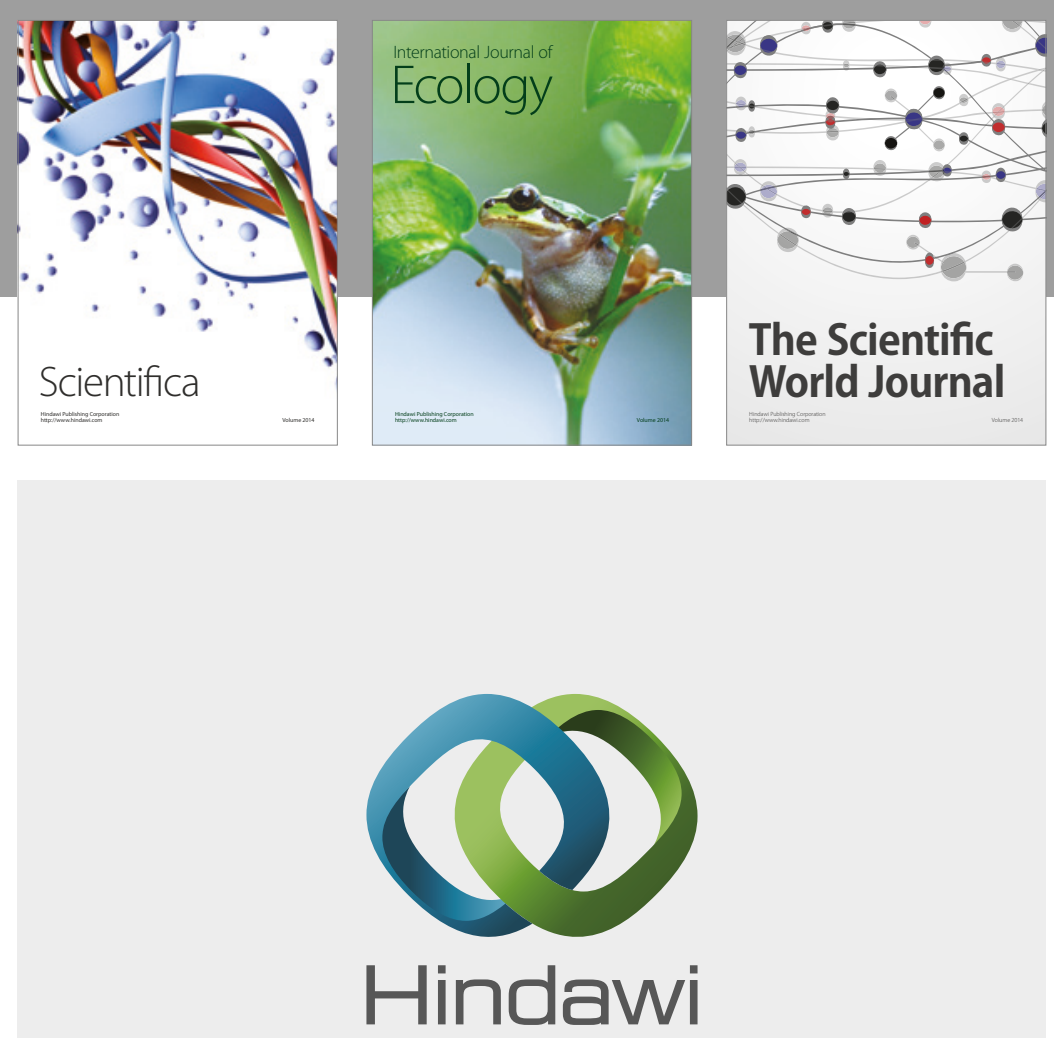

Submit your manuscripts at

https://www.hindawi.com
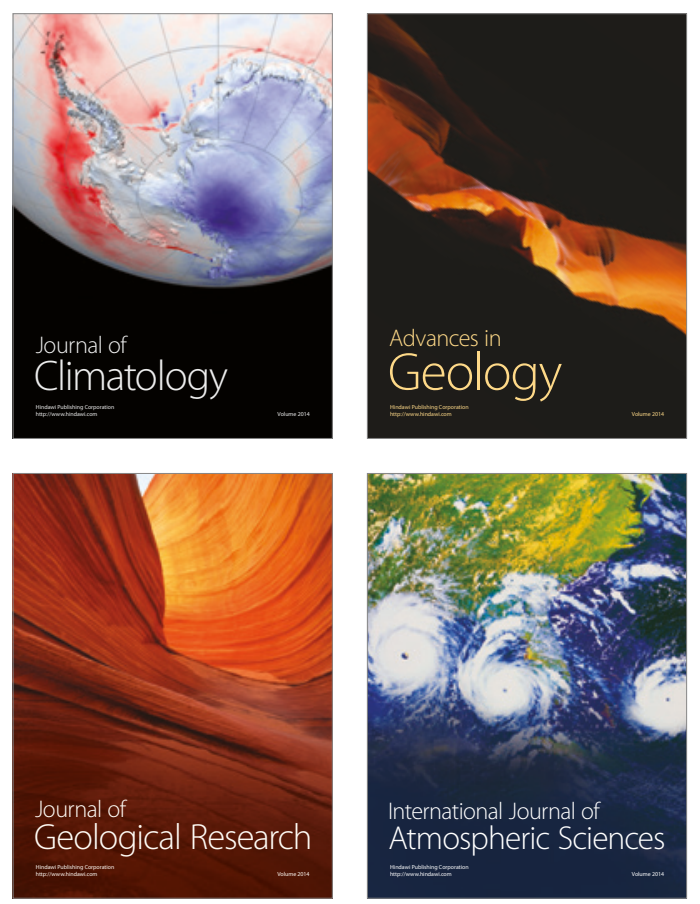

The Scientific

World Journal
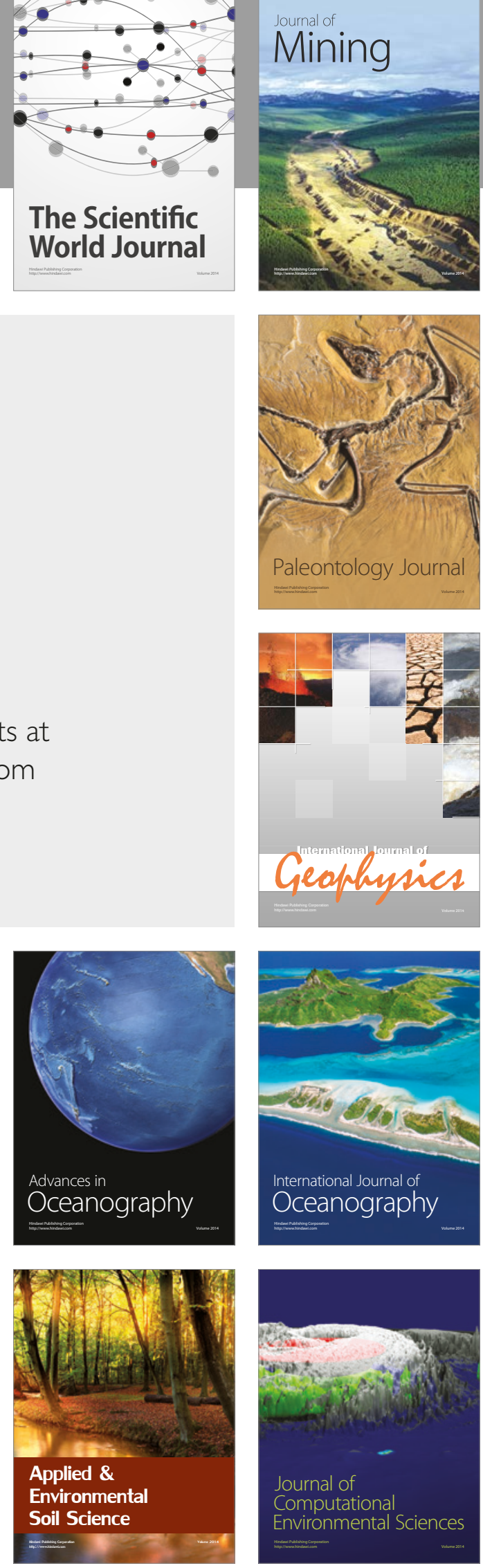